San Jose State University

SJSU ScholarWorks

Master's Theses

Master's Theses and Graduate Research

1989

\title{
The Effects of involvement, majority position, and quality of majority and minority arguments on choice shift in small groups
}

Stephen Andrew March

San Jose State University

Follow this and additional works at: https://scholarworks.sjsu.edu/etd_theses

\section{Recommended Citation}

March, Stephen Andrew, "The Effects of involvement, majority position, and quality of majority and minority arguments on choice shift in small groups" (1989). Master's Theses. 3093.

DOI: https://doi.org/10.31979/etd.2q3s-9586

https://scholarworks.sjsu.edu/etd_theses/3093

This Thesis is brought to you for free and open access by the Master's Theses and Graduate Research at SJSU ScholarWorks. It has been accepted for inclusion in Master's Theses by an authorized administrator of SJSU ScholarWorks. For more information, please contact scholarworks@sjsu.edu. 


\section{INFORIMATION TO USERS}

The most advanced technology has been used to photograph and reproduce this manuscript from the microfilm master. UMI films the text directly from the original or copy submitted. Thus, some thesis and dissertation copies are in typewriter face, while others may be from any type of computer printer.

The quality of this reproduction is dependent upon the quality of the copy submitted. Broken or indistinct print, colored or poor quality illustrations and photographs, print bleedthrough, substandard margins, and improper alignment can adversely affect reproduction.

In the unlikely event that the author did not send UMI a complete manuscript and there are missing pages, these will be noted. Also, if unauthorized copyright material had to be removed, a note will indicate the deletion.

Oversize materials (e.g., maps, drawings, charts) are reproduced by sectioning the original, beginning at the upper left-hand corner and continuing from left to right in equal sections with small overlaps. Each original is also photographed in one exposure and is included in reduced form at the back of the book. These are also available as one exposure on a standard $35 \mathrm{~mm}$ slide or as a $17^{\prime \prime} \times 23^{\prime \prime}$ black and white photographic print for an additional charge.

Photographs included in the original manuscript have been reproduced xerographically in this copy. Higher quality $6^{\prime \prime} \times 9^{\prime \prime}$ black and white photographic prints are available for any photographs or illustrations appearing in this copy for an additional charge. Contact UMI directly to order.

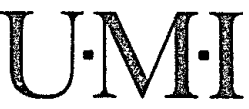



Order Number 1937827

The effects of involvement, majority position, and quality of majority and minority arguments on choice shift in small groups

March, Stephen Andrew, M.A.

San Jose State University, 1989 

THE EFFECTS OF INVOLVEMENT, MAJORITY POSITION, AND QUALITY OF MAJORITY AND MINORITY ARGUMENTS ON CHOICE SHIFT IN SMALL GROUPS

\author{
A Thesis \\ Presented to the Faculty \\ of the Department of Communication Studies \\ San Jose State University
}

In Partial Fulfillment

of the Requirements for the Degree

Master of Arts

by

Stephen Andrew March

May, 1989 
APPROVED FOR THE DEPARTMENT OF COMMNICATION STUDIES

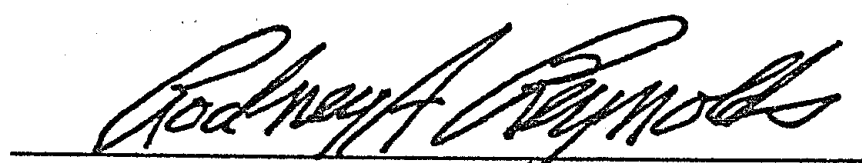

Dr. Rodney Reynolds

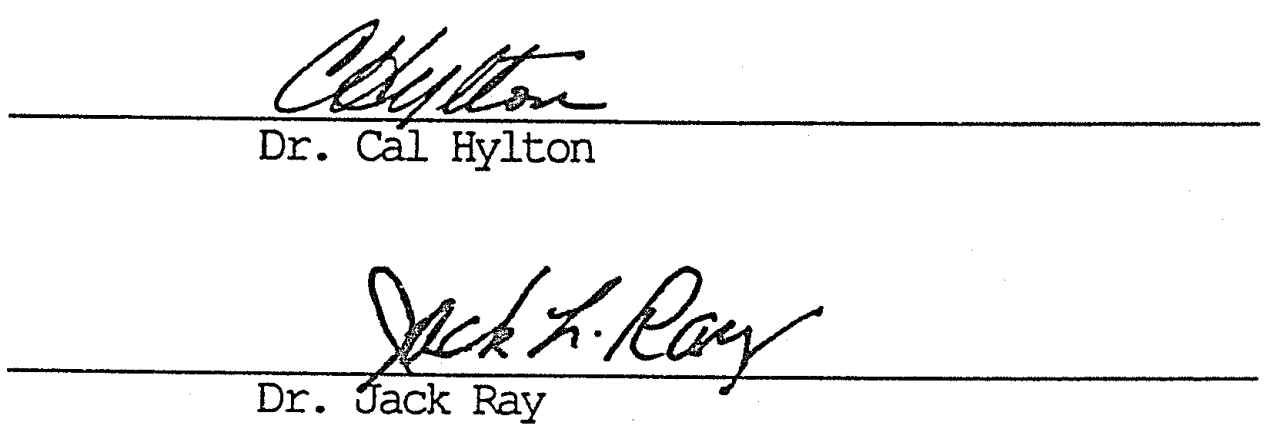

APPROVED FOR THE UNIVERSITY

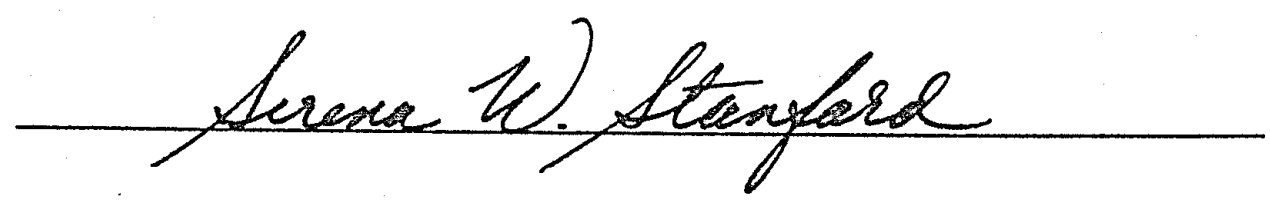

ii 


\section{ACKNOWLEDGMENTS}

First, to my wife Laurie, my undying gratitude for her love and her help throughout this project. Her typing and editing skills have been invaluable. She is my constant motivation to press onward. She has been my partner in the truest and best sense of the word.

To my parents, I am indebted for all of their support, both moral and financial. They have always been an encouragement in my pursuit of higher education. I am also grateful for the values that they have instilled in me.

Dr. Rodney Reynolds has been not only a superb advisor, but also a good friend. I have benefited from his advice in academic affairs, his guidance in research, and his concern in personal matters.

Dr. Cal Hylton and Dr. Jack Ray were available to help whenever I needed it. Their comments were always insightful and useful. Special thanks to Dr. Hylton, in whose class the original idea for this study was spawned.

Finally, I thank God, who makes all things possible. He has made my life worth living. I dedicate my life and my work to Him. 
TABLE OF CONTENTS

CHAPTER

PAGE

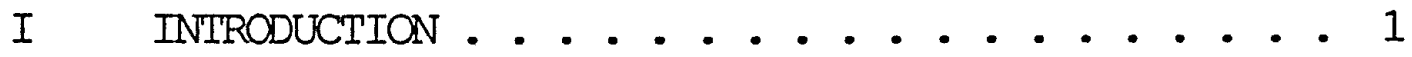

II REVIEW OF RELATED LITERATURE . . . . . . 6

Social Comparison . . . . . . . 6

Persuasive Arguments . . . . . . 8

Differential Perceptions of Argument

Quality ........... 9

Involvement Effects ........ . 12

Overview ............. 22

Statement of the Hypothesis . . . . . . . 23

III EXPERTMENT 1............. 25

Methods .............. 25

Results ............ 33

Discussion ............... 36

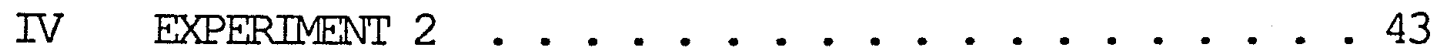

Methods .............. . 43

Results .................... 47

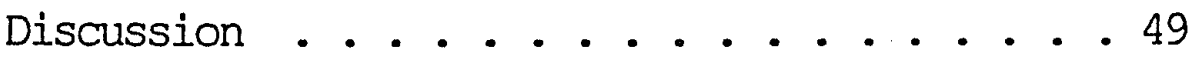

V GENERAL DISCUSSION: EXPERTMENT 1

AND EXPERTMENT 2 ............ 54 
Hypothesis . . . . . . . . 54

Additional Findings . . . . . . . . 54

Limitations . . . . . . . . . 55

Future Research . . . . . . . . 57

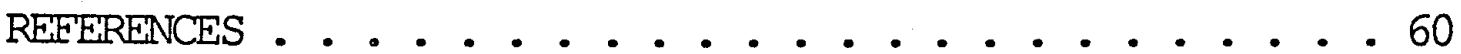

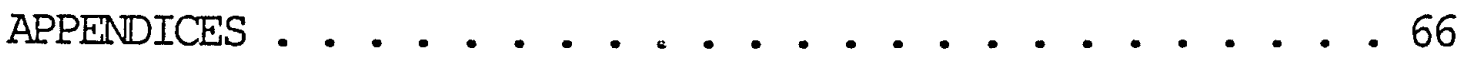

Appendix A. Pilot Test Booklet . . . . . 67

Appendix B. Experiment 1

Stimulus Items . . . . . . . 78

Appendix C. Posttest Instruments for

Experiment 1 and Experiment 2 ..... 91

Appendix D. Experiment 2

Stimulus Items . . . . . . . . . 94

Appendix E. Human Subjects Approval

Form ............. 103 


\section{LIST OF TABLES}

TABLE

PAGE

1. Means for Attitude Measure by Message Elaboration and Argument Quality ... . . . 40

2a. Means for Attitude Measure by Manipulation of Involvement, Majority Position, and Argument Quality .... . . . 4 41

2b. ANOVA Table for Experiment 1 ........ . 42

3a. Means for Attitude Measure by Manipulation of Involvement, Majority Position, and Argument Quality ... . . . . 52

3b. ANOVA Table for Experiment 2 . . . . . 53 
Chapter 1

Introduction

In the past three decades a significant body of research has been undertaken in the study of attitude shifts following group discussions. Stoner (1961, cited in Myers \& Lamm, 1976) found that groups made decisions that were more risky than the decisions made by the individual group members. In much of the choice shift research that ensued, the choice dilerma item has been the preferred stimulus. The choice dilerma item developed by Kogan \& Wallach (1964), typically features a fictional character facing a decision. For example, the employment item (Stoner, 1968) describes a college graduate deciding between a job offer from a new fim with wiuch opportunity for advancement but an uncertain future, and an offer from an established firm with a solid future but low growth potential. Generally, individual subjects advise the character as to what amount of risk is acceptable to take in choosing the potentially more rewarding alternative (i.e., the character should accept the offer from the new firm if the chances are at least 6 in 10 that the new firm will succeed), and then meet in groups to discuss the decision until consensus is reached.

Stoner made the observation that groups make decisions which are riskier than the decisions made previously by the individual members of the group. Subsequently, it has been 
shown that shifts may occur in a risky or cautious direction and that the tendency for the choice shift phenomenon to occur is very prevalent in small groups (Myers \& Lamm, 1976).

Researchers apparently have not been able to agree on whether the group attitude shift phenomenon should be labeled group polarization or choice shift, or if there is a difference between the two. Some researchers (Laughlin \& Earley, 1982; Meyers \& Seibold, 1988) distinguish between the two by stating that choice shift is the difference between mean individual prediscussion attitudes and the collective group decision, while group polarization is the difference between mean individual pre- and postdiscussion attitudes as a result of the group discussion. However, the importance of the distinction between group decisions and mean individual. postdiscussion attitudes has not always been supported by research (see Laughlin \& Earley, 1982). Other researchers (e.g., Boster \& Mayer, 1984; Cotton \& Baron, 1980; Kellemann \& Jarboe, 1987) use choice shift and group polarization synonymously.

Group polarization is not an ideal label for the group attitude shift phenomenon for two reasons. First, polarization is not an appropriate description for group attitude shifts which have been observed in the direction of neutral or moderate attitudinal positions (see Vinokur \& Burnstein, 1978). Second, the term polarization is ambiguous 
in that polarization also refers to a bi-directional effect in which two subgroups in an audience or a group represent opposite ends of an attitudinal continuum (cf., Myers \& Lamm, 1976). Therefore, for the sake of clarity, the term choice shift will be used for the purposes of this study.

Choice shift occurs when the attitudes of group members become more extreme in the direction of the already preferred position following a group discussion. Choice shift is the difference between what individuals would decide on their own and what group members decide following interaction.

A review of the choice shift literature reveals that much of the literature implies that choice shift is a dysfunctional process. For example, according to Kellemann and Jarboe (1987) in choice shift research, "the constant has been the comparison of the group to indivicuals acting alone with the assumption that indivicuals acting alone provide an accurate and adequate standard of comparison" (p. 261). While implications of the dysfunctionality of choice shift are prevalent, the assumption that choice shift is dysfunctional is seldomly stated formally, and rarely explained.

When attitudes change on the basis of comparing one's own attitudes with the attitudes of other group members without considering the basis of those attitudes (i.e., social comparison), or on the basis of a one-sided 
representation of arguments within the group, choice shift is a dysfunctional group process. When the choice shift results from proportional representation of arguments for both sides of an issue and group members make thoughtful decisions, based on evaluations of argument quality, then choice shift may be a beneficial group decision-making function. The process of groups becoming more extreme than indivicuals may or may not be dysfunctional. Group dysfunction is not a necessary component of the choice shift effect.

Choice dilemma items are usually categorized by their tendency to produce risky, cautious, or neutral shifts. Shifts have been observed in all three cases (Vinokur \& Burnstein, 1978). Kellermann and Jarboe (1987) argue that shifts should be examined in terms of an information processing optimum, rather than in terms of risk or caution. Kellermann and Jarboe propose that the choice shift research has operated under the assumption that individuals operate at an optimal level of risk-taking in decision making, and provide the appropriate standard for comparison (Kellemann \& Jarboe, 1987, p. 261). However, if indivicuals do not perform at an optimal level of risk-taking, groups may shift in an optimal, rather than risky or cautious direction. According to Kellemann and Jarboe the group may serve as a deterrent against the tendency of indivichals to engage in sub-optimal infomation processing. The group may more 
closely approach, though still not reach, an optimal level of information processing and provide arguments and information about the reliability (i.e., other group members' acceptance) of the arguments for the individual. 
Chapter 2

Review of Related Literature

In the past, choice shift studies have generally argued from the perspective of either social comparison or persuasive arguments processes (Miller, 1978; Isenberg, 1986). Miller accused choice shift research of "theoretical chauvinism," charging that researchers tend to argue for their own preferred explanation to the complete exclusion of all other possible explanations. In recent work (e.g., Boster \& Mayer, 1984; Isenberg, 1986; Myers, Bruggink, Kersting \& Schlosser, 1980; Whitney \& Smith, 1983), however, many researchers propose that both social comparison and persuasive arguments processes contribute to choice shifts. The following discussion is divided into separate discussions of social comparison processes, persuasive arguments theory, a model based on differential perceptions of argument quality presented by Boster and Mayer (1984), and the relationships based on involvement predicted by the current study.

\section{Social Comparison}

The social comparison explanation of choice shift originates from the view that people desire to be perceived as socially desirable. When group discussion reveals to some members of the group that they fail to equal the average group member on a valued dimension, choice shift occurs to the extent that these members shift their attitudes in the 
positively valued direction. The social comparison process would foster the prediction that the choice shift would occur in the direction of the majority position (Laughlin \& Earley, 1982).

Findings that knowledge of other group members' positions alone can produce a choice shift provide support for the social comparison explanation. Myers, Wojcicki, and Aardema (1977) had 169 subjects respond on agreement/ disagreement scales to 16 statements. Subjects responded in a control condition, or after being provided with either the average response or a frequency distribution of the responses of 100 previous subjects' responses. Subjects in both the average-exposure and frequency-exposure conditions showed significant attitude shifts, with no significant difference between the two.

Subjects in a 1980 study by Cotton and Baron first responded privately on four jury items and on four choice dilenma items (Cotton \& Baron, 1980). Following exposure to other group members' ratings, subjects then responded in either anonymous or public conditions. Subjects exhibited choice shifts in both conditions. Cotton and Baron also found that social comparison information did not lead subjects to generate significantly more arguments than subjects who were not exposed to social comparison information. This finding is significant because Burnstein, 
Vinokur, and Trope (1973) contend that social comparison information serves only to stimulate subjects to generate persuasive arguments.

\section{Persuasive Arguments}

The persuasive arguments hypothesis proposes that group members shift their attitudes as a result of the arguments they are exposed to during group interaction. Laughlin and Earley (1982) argue that a choice shift occurs to the extent that group members are convinced of the worth of previously unconsidered arguments. Thus, predicting from a persuasive arguments viewpoint, the observed shift would occur in the direction of the side which advances the arguments judged by the group member to be higher quality arguments.

Some of the strongest support for persuasive arguments theory has come from research pursued by Eugene Burnstein and Amiram Vinokur (e.g., Burnstein \& Vinokur, 1973, 1975; Burnstein, Vinokur, \& Trope, 1973; Vinokur \& Burnstein, 1974, 1978). Vinokur and Burnstein (1978) argue that one situation where persuasive arguments and social comparison processes make contrary predictions is in the case of subgroups. When group members are split into two sides which favor opposing views, social comparison fosters the prediction that individuals' attitudes will become more extreme, in the direction preferred by their subgroup, as a result of comparing their own attitudes with the attitudes of those in 
their subgroup. The result would be a larger difference between the mean attitudes of the two subgroups. However, persuasive arguments theory fosters the prediction that depolarization between subgroups should occur as a result of exposure to the opposing side's arguments. When such subgroups were created within groups, massive depolarization effects were obtained. These results were consistent with reasoning from a persuasive arguments theory viewpoint regarding subgroups.

Differential Perceptions of Argument Quality

Some researchers propose that whether social comparison or persuasive arguments processes will occur may be a result of factors such as the type of task the group faces (Laughlin \& Earley, 1982), or the preferred decision strategy of the group (Whitney \& Smith, 1983). Many choice shift studies use choice dilerma items which can be arranged on a continuum ranging from highly intellective to highly judgmental (Laughlin \& Earley, 1982).

Highly intellective items have a demonstrably correct solution, and are identified by extremely skewed pretest attitude scores. Highly judgmental items are subjective in nature, require group consensus, and are identified by relatively nomally distributed pretest attitude scores.

Boster and Mayer (1984) contend that for judgmental items both social comparison and persuasive arguments 
processes occur and that perceptions of argument quality are affected by social comparison processes. Boster and Mayer further speculate that independent manipulations of majority and argument quality would be impossible for judgmental items, but admit that it is unclear what role personal involvement would play in this interaction (Boster \& Mayer, 1984, p. 407). Specifically, Boster and Mayer hypothesize that for a judgmental item, manipulation of the majority position will incuce a social comparison process which, in turn, has a positive effect on the perceptions of the quality of persuasive arguments. The direction and magnitude of the choice shift are then directly affected by the perception of the quality of persuasive arguments.

Subjects in Boster and Mayer's (1934) study rated their opinion on a choice dilemma item, read a contrived script of a group discussion which varied the majority position and the quality of each side's arguments, and then completed a posttest rating of their opinion. While Boster and Mayer's data clearly show that their subjects perceived the majority's arguments to be of higher quality than the minority's arguments, their interpretation is open to question.

Boster and Mayer's use of a choice dilemma item may account for the subjects' perceptions of argument quality being affected by the majority manipulation. McLachlan 
(1986) found that subjects were better able to distinguish preferred from non-preferred argument sets on attitude issues, which were rated by subjects as involving, than on the choice dilema items which subjects rated as less involving. It may be that when faced with levels of argument quality which were difficult to distinguish, subjects rated the arguments using the majority as their only reference. March and Reynolds (1988) used a majority manipulation identical to Boster and Mayer's (1984), but did not observe a majority position effect on ratings of argument quality when subjects read a contrived script of a group discussion on the attitude issue of living together before marriage. It may be that the majority effect on perceptions of argument quality that was observed by Boster and Mayer (1984) varies with the topic that is used or the type of item (i.e., attitudinal or choice dilemma), or that there is a more complicated relationship between majority position and perceptions of argument quality.

It is also possible that social comparison processes took place, but that social comparison was induced by a lack of involvement, rather than by the majority position. The choice dilemma item used as a stimulus may have generated sufficiently low involvement for the subjects that they were not motivated to engage in issue-relevant thinking and therefore engaged in social comparison processes. Choice 
dilema items such as the employment item, or the medical school-music school problem may be of a nature such that subjects do not become sufficiently involved in role-playing and issue-relevant thinking is not incuced (cf., Petty \& Cacioppo, 1979). For example, it may be unrealistic to expect a freshman art major to become involved in advising a college business graduate as to which fim to accept a job offer from, as in the employment item. Thus, if a social comparison process took place, the majority manipulation would serve as a cue to help the subjects determine the socially acceptable position.

Therefore, it is possible that choice dilemma items do not allow for inducement of either social comparison or persuasive arguments processes on judgmental items. Choice dilemma items also may not allow for the separate manipulation of majority position and argument quality on judgmental items.

\section{Involvement Effects}

One variable which may also mediate the comparative explanatory power of the social comparison and persuasive arguments approaches is involvement. March and Reynolds (1988) found that highly involved subjects were more likely to agree with the side which presented higher quality arguments regardless of the majority position and that lowinvolved subjects were more likely to be persuaded by the 
majority even when the minority presented higher quality arguments. Several researchers (Axsom, Yates, \& Chaiken, 1987; Chaiken, 1980; Petty, Cacioppo, \& Goldman, 1981) have shown that higher levels of involvement increase messagerelevant thinking and that under lower levels of involvement subjects are more influenced by nonmessage-relevant cues. If involvement is a factor in the choice shift phenomenon, it may be that high levels of involvement will foster persuasive arguments processes and low levels of involvement will foster social comparison processes.

One possible explanation of such an involvement effect in choice shift processes is found in the heuristic model of persuasion (Chaiken, 1980). The following sections will turn to an explanation of the heuristic model of persuasion, a review of the relevant research on involvement, and a discussion of the concept of contextual processing demands. The Heuristic Model

The heuristic model of persuasion (Chaiken, 1980) distinguishes between two processing strategies, labeled the systematic processing strategy and the heuristic processing strategy, which may be engaged in by individuals exposed to a persuasive message. In the systematic processing strategy, message-based cognitions mediate persuasion. When heuristic processing occurs judgments are made on the basis of simple decision rules. Motivation and ability to engage in message- 
and issue-relevant thinking are the major factors affecting which strategy will be chosen.

The heuristic strategy demands less cognitive effort and therefore is more economical in terms of cognitive capacity. However, taking advantage of this reduced effort, may result in an increase in the number of incorrect judgments about the validity of persuasive messages [i.e., "recipients may sometimes accept (reject) message conclusions they might otherwise have (correctly) rejected (accepted) had they invested the time and effort to receive and scrutinize argumentation" (Chaiken, 1980, p. 754)].

Chaiken (1980) views issue involvement as an important factor in the process of deciding what messages warrant careful examination. Chaiken argues that people detemine which messages they will examine on the basis of whether reliability concerns or economic concerns are judged to be of more importance. Chaiken proposes that when a message recipient is involved in the message issue, the recipient will judge reliability concerns to be more important than economic concerns and will expend the effort to analyze message arguments. In short, issue involvement fosters a systematic processing strategy. However, if the message recipient is not involved in the issue, economic concerns may outweigh reliability concerns. That is, with low issue involvement the recipient may employ a heuristic processing 
strategy to judge the acceptability of a message on noncontent cues (e.g., credibility, perceived audience opinion, communicator attractiveness).

Consistent with these predictions, Axsom, Yates, and Chaiken (1987) employed the heuristic processing model to explain intra-audience effects (see Hylton, 1971; Hocking, Margreiter, \& Hylton, 1977). Axsom et al. found that subjects listening to an audiotaped persuasive message were influenced by audience response only under low involvement conditions and were influenced by argument quality only under high involvement conditions. The social comparison process in the small group setting seems intuitively linked to intra-audience effects (Olds, 1980). In both contexts, individuals rely on the observable behavior of people within the social gathering to decide how to respond. Involvement

A distinction must be made between three types of involvement. The first type of involvement, ego-involvement, has been defined in social judgment theory as an individual's latitude of rejection (Sherif, Kelly, Rodgers, Sarup, \& Tittler, 1973; Sherif \& Sherif, 1967). A second type of involvement, issue involvement (Kiesler, Collins, \& Miller, 1969; Petty \& Cacioppo, 1979), is defined by Petty and Cacioppo as the extent to which the issue under consideration is of personal importance to the individual. The third type 
of involvement is created using a manipulation of instruction sets that the subjects are exposed to. According to Axsom, Yates, and Chaiken (1987) some experimental settings probably induce high involvement in terms of motivation to expend cognitive effort. In short, Axsom et al. propose what could be called contextual processing demand (CPD) as a type of involvement. In high CPD situations subjects are exposed to instructional sets which encourage cognitive effort (e.g., "pay careful attention"). Low CPD situations are those in which processing demands are absent and subjects are encouraged to conserve cognitive effort. In order to counter pressures toward increased cognitive effort, Axsom, Yates, and Chaiken included a comedy tape and cookie-tasting in their experiment, and a low CPD instruction set (e.g., "just sit back and relax," Axsom, Yates, \& Chaiken, 1987, p. 32).

Isenberg (1986, p. 1149) speculates that ego-involvement should cause social comparison processes to operate more strongly. Isenberg (1986) states that the parameters of the group change when the issue is involving to group members. According to Isenberg, social comparison processes should be more likely to operate when the issue is involving to group members because argument pools tend to be exhausted since the issues have been heavily processed by engaged individuals.

Although Isenberg uses the term ego-involvement, which comes from the social judgment-involvement approach to 
attitude change, he does not reference social judgment theory as the basis of his speculation, and his predictions regarding choice shifts share very little in comnon with social judgment theory. Social judgment theory does not distinguish between social comparison and persuasive arguments processes. Rather, social judgment theory is concerned with an individual's perceptions of the degree of similarity between the individual's own position and the position advocated in a communication. According to social judgment theory, this perceived degree of similarity is brought about by a combination of the ambiguity of the message, the identity of the communicator, and the actual discrepancy between the two positions. Once the individual places the communication in terms of similarity, attitude change occurs as a function of discrepancy (Granberg, 1982). The less involved a person is with an issue, the more susceptible that person is to persuasive attempts. Higher ego-involvement individuals show less attitude change in response to moderately or highly discrepant messages. Highly discrepant messages will induce reverse attitude change from the advocated position for highly ego-involved persons (i.e., a boomerang effect). Thus, in social juagment theory perceived discrepancy is a more important characteristic of the message than is the argument or comparison information contained by the message. 
In any case, if Isenberg's (1986) suggestion stems from the operational definition of ego-involverent used in social judgment theory, the apparent assumption that arguments which are already known by the subject, and which are discrepant from the subject's position, will be dismissed is inappropriate since axiomatically a cersuasive argument Falling within an individual's latitude of rejection will be contrasted (i.e., the discrepancy between ccmunicator's position and the subject's cosition will be overestimated) and will ultimately result in reverse attitude change from the acirocated position.

Actually, the argument can be made from a social judgment position, that increasing ego-involvement could lead to increased message elaboration even for discrepant rressages. Sherif et al. (1973) established that egoinvolvement, as defined by the latitude of rejection, was related to the salience of reference groups in which the issue under investigation vas a priority. If it can be essined that the individual's latitude of rejection is a "otion of the position espoused by his or her reference :-vup, then an indivicual who is a member of a group that is " favor of a counterattitudinal position might find the juments raised by the group to be less discrepant and be willing to prccess those arguments rather than rejecting them immediately as Isenberg (1986) suggests. 
It is important to realize that there is a difference between the willingness to process arguments on the basis of a perception of the discrepancy between the persuasive arguments and one's own position, and a differential perception of argument quality based on social comparison as suggested by Boster and Mayer (1984). If perceptions of the discrepancy between the persuasive arguments and one's own position are reduced, the individual should be more likely to process the arguments espoused by the majority, but perceptions of argument quality should be unaffected. If social comparison affects judgments of argument quality, an argument espoused by the majority should be perceived as higher in quality than an argument espoused by the minority. Involvement is conceptually defined as the level of intrinsic importance of an issue to the person (Sherif \& Hovland, 1961), the extent to which the person expects the issue to have significant consequences for his or her life (Apsler \& Sears, 1968), and the level of personal meaning the issue has for the person (Sherif et al., 1973). Involvement can best be described as the salience or relevance of an issue to the individual subject. This conceptual definition seems most closely related to the concept of issue involvement.

If the conceptual definition of involvement is used, the argument for a simple positive relationship between 
involvement and sccial comparison effects seems uncompelling, since the underlying premise appears to be that individuals involved with an issue are blind to persuasive arguments other than those they currently adhere to. Indeed, a stronger case could be made that high involvement is linked to a persuasive arguments process.

Involvement can increase the likelihood of argument processing by an individual. Miller, Maruyama, Beaber, and valone (1976) suggest that the number of counterattitudinal messages a person receives each day probably surpasses the person's available time and capacity for information processing. In order to handle such overload, persons must have some basis for deciding which messages are worthy of careful examination and which are not. Petty, Cacioppo, and Golcman (1981) argue that involverent with the issue is a key factor in determining which messages people will examine.

Issue involverment was shown by Petty and Cacioppo (1979) to ke one factor which motivated message elaboration. They fourd that increasing issue involvement enhanced message elaboration, thereby increasing persuasion for messages with arguments that pilot test subjects responded to favorably and decreasing persuasion for messages with arguments that pilot test subjects responded to unfavorably.

Isenberg's (1986) assumption that sccial comparison processes occur when people are blind to persuasive arguments 
would seem to be more descriptive of low issue involved individuals who employ heuristic processing. Low issue involved individuals would not be motivated to extend much cognitive capacity for message processing and would be more likely to engage in heuristic processing (Chaiken, 1980; Chaiken \& Eagly, 1983).

If issue involvement enhances message elaboration in a small group discussion setting, it would be expected that for a highly issue involved individual the quality of the arguments would be a better predictor of attitude shift than would be the majority of the group, thereby indicating a persuasive arguments process. In the absence of other motivating factors, however, for an individual who is not highly issue involved, the attitudinal position of the majority of the group should be a better predictor of attitude shift than would be the quality of the arguments, thus indicating a social comparison process. Contextual Processing Demands.

Axsom, Yates and Chaiken (1987), argue that experimental settings may also encourage systematic processing. That is, the experimental setting may contain explicit demands to process, and thus, systematic processing is encouraged. In other situations, however, explicit demands to process may be absent and the indivicual may feel encouraged to conserve cognitive effort, and engage in heuristic processing. High 
CPD instruction sets may be those which inform the subject of the importance of the experiment and instruct him or her to pay close attention to the task. In contrast, low CPD instruction sets are those which minimize the importance of the experiment and encourage the subject to relax. Axsom, Yates, and Chaiken (1987) found that high involvement in the form of either issue involvement or processing demands fostered systematic processing, but when subjects were in low CPD situations and were low in issue involvement they were more likely to engage in heuristic processing. Thus, CPD can be held low as a constant in order to better observe the effects of issue involvement. With low CPD, high issue involvement should still incuce elaboration of message arguments. Low issue involvement subjects should regard the low CPD cues as dismissing the need to elaborate on message arguments, but should be influenced by the majority position.

\section{Overview}

Working from within the framework of the heuristic model of persuasion, a review of the above literature leads to the conclusion that involvement may be an important factor in detemining when persuasive arguments processes will occur and when social comparison processes will occur. The purpose of this study was to examine the relationship of issue 
involvement to social comparison and persuasive arguments processes in terms of the heuristic model of persuasion. The heuristic model of persuasion fosters the prediction that in low CPD conditions, low issue involved indivichals would be likely to engage in social comparison processes resulting in a choice shift, while high issue involved individuals would be likely to engage in higher levels of message elaboration and choice shift should result from persuasive arguments processes. This assumption can be tested by creating conditions in which the majority position and the quality of the arguments on each side of the issue are varied. It was predicted that in low CPD conditions the low issue involved subjects would be more influenced by the majority position in the group than by the quality of the arguments, indicating a social comparison process. However, it was predicted that in low CPD conditions the high issue involved subjects would be more influenced by the quality of the arguments than by the majority position in the group, indicating a persuasive arguments process.

\section{Statement of the Hypothesis}

The review of literature resulted in the generation of the following hypothesis:

$\mathrm{H}^{1}$ : There is an interaction between issue involvement, argument quality and majority position such that: 
(a) Subjects with high levels of issue involvement will report attitudes more similar to the position held by the member(s) whose arguments are perceived as high in quality, regardless of majority position, and

(b) Subjects with low levels of issue involvement will report attitudes more similar to the majority position, regardless of perceptions of argument quality, following a simulated group discussion. 


\section{Chapter 3}

Experiment 1

Methods

Subjects

Subjects were volunteer undergraduate students enrolled in introductory communication courses at San Jose State University. Prior research (e.g., Boster \& Mayer, 1984; March \& Reynolds, 1988) led to the conclusion that it was appropriate to look for an effect size of at least .11. A power analysis was performed to determine that 228 subjects were needed to provide a chance equal to .80 of finding an effect size equal to .11 if it did exist. Two hundred fortynine subjects participated in the study. Subjects were randomly assigned to treatment conditions.

\section{Pilot Test}

First, a pilot test of attitudes and perceptions of the quality of various arguments on several issues was performed on a sample of individuals taken from the same population that subjects were drawn from. The purpose of this pilot study was to select an issue which provided a relatively nomal distribution of attitudes. A nomal distribution of attitude was selected as the criteria for selecting a judgmental item (Laughlin \& Earley, 1982). Manipulations of involvement were tested to insure selection of an item that would provide significant differences on perceptions of 
involvement. Manipulations of argument quality were also tested to assure significant differences in perceptions of high and low quality arguments on both sides of the issue. Pilot test subjects $(\mathbb{N}=59)$ received one of two booklets (see Appendix A) containing three of six issues. The six issues were: (a) requiring employees and students to provide their employers and/or schools with the results of an AIDS detection test, (b) requiring comprehensive examinations for graduation from college, (c) an additional $\$ 50.00$ registration fee in place of parking fee increases, (d) requiring employees to provide their employers with the results of a drug detection test, (e) eliminating social security withholding taxes and requiring employees to provide proof of a personal retirement plan, and (f) requiring students to carpool or shuttle to carpus.

Pilot test subjects first indicated their attitude toward each of the three issues in their booklet on standard semantic differential-type scales with the anchors good-bad, valuable-worthless, beneficial-harmful, and desirableundesirable. Next, subjects read either a high or low involvement manipulation for each of the three issues and responded on three semantic differential-type scales for each issue as to how important the issue was to them (very important-not at all important), the extent to which they expected the issue to have significant consequences for their 
life (very significant-not at all significant), and what level of personal meaning the issue held for them (very meaningful-not at all meaningful). Pilot test subjects then read a set of high or low quality arguments in support of the proposition and a set of high or low quality arguments opposing the proposition. Finally, the quality of each argument set was rated on a set of four semantic differential-type scales with the anchors strong-weak, convincing-unconvincing, persuasive-lacking in persuasiveness, and reasonable-unreasonable.

Significant differences in involvement as a result of the pilot test manipulations were only obtained for the issues of comprehensive examinations and requiring students to carpool or shuttle to campus. The carpool issue was rejected because the mean attitude was negative $\underline{M}=2.07$, Scale Range $=1-7$ ) and the issue had a skewness $=.98$.

The issue of requiring comprehensive examinations for graduation from college best met the topic selection criteria as evidenced by pilot test results. The mean attitude toward comprehensive examinations was 4.01 on a seven-point scale. The median score was 4.13. The issue had a skewness of -.20 . Procedures

Subjects received one of twelve versions of the stimulus booklet containing a brief description of the issue to be discussed, a one-page script entitled "Excerpt From a Group 
Discussion," a posttest measure of attitude, manipulation check items, and a measure of message elaboration. The twelve booklet versions differed in the manipulation of issue involvement (high, low), majority position (for, against, no majority), and argument quality (majority high/minority low, majority low/minority high). The order of the manipulation check items and the message elaboration scale were randomized across all conditions.

When subjects received the booklet, they were asked to relax and not put much cognitive effort into the task before them (low CPD instructions). Subjects were then instructed to read the script and respond to the items following the script as if they were members of the group in the discussion. Following completion of these items, subjects were thanked and debriefed. Independent Variables

Issue involvement. Issue involvement was manipulated by varying the description of the extent to which the issue would have an effect on the subject's life (see Appendix B). In short, the low issue involvement condition contained a script in which comprehensive examinations were being discussed for possible implementation at colleges in the state of Georgia in three years. In the high issue involvement condition the script stated that comprehensive examinations were being discussed for possible 
implementation at the subject's own university the following semester.

The manipulation check of issue involvement contained three seven-point semantic differential-type scales (see Appendix C). The scale anchors consisted of sentence completions representing the subject's feelings about the issue of comprehensive examinations in terms of how important it was to them (very important-not at all important), how significant would the consequences be for their life (very significant-not at all significant), and how meaningful the issue was to them (very meaningful-not at all meaningful).

Majority. The majority was created by having three out of four group members in favor of (opposed to) an extreme position on the selected topic (see Appendix B). The fourth member was opposed to (in favor of) the extreme position. The script consisted of an experimenter internupting a group discussion to poll the attitudes of its members. The first speaker took the majority position and offered three strong (weak) arguments to support that position. The second speaker always took the minority position and offered three weak (strong) arguments in support of that position. The third and fourth speakers indicated agreement with the first speaker, but offered no new arguments. In the no majority condition, the first speaker was in favor of (opposed to) and the second speaker was opposed to (in favor of) the extreme 
position on the topic. The third speaker indicated agreement with the first speaker, but offered no new arguments. The fourth speaker indicated agreement with the second speaker, but offered no new arguments. Order was held constant since Boster and Mayer's (1984) study indicates that order had no main effect on opinion change and did not interact with any other independent variables to affect opinion change. In order to check that the majority/minority position manipulation was effective, the subjects responded to an item asking whether the majority had been in favor of or opposed to the proposal for examinations, or if there had been no majority (see Appendix C) .

Argument quality. Argument quality was manipulated by varying the quality of the arguments in favor of the proposition (high, low) and the quality of the arguments opposed to the proposition (low, high). Students in small group comminication courses at San Jose State University were asked to generate arguments which they perceived as high and low in quality on both sides of the issue. These arguments were then rated as high or low in quality by pilot test subjects. Three high quality arguments and three low quality arguments were selected for each side of the issue from these ratings (see Appendix B). The subjects made judgments of the quality of the arguments on four seven-point scales with the anchors strong-weak, reasonable-unreasonable, convincing- 
unconvincing, and persuasive-lacking in persuasiveness (see Appendix C) .

The strong arguments in favor of comprehensive examinations stated that the examinations should be a graduation requirement because: (a) graduates who have taken comprehensive examinations are ranked as more desirable by most employers so this policy would improve job opportunities for graduates, (b) examinations would give students incentive to study harder and learn more, and (c) this policy would insure that graduates have adequate skill levels. The weak arguments in favor of the examinations supported the policy because: (a) college students have it too easy right now, (b) examinations will let the student know if he/she is any good, and (c) testing builds character.

The side opposing comprehensive examinations had strong arguments against the policy which stated that: (a) a paper and pencil test cannot accurately measure the performance skills necessary to most careers, (b) a fair test would be impossible to develop, and (c) it would be redundant to test students on subject matter from classes that they have already passed. The weak arguments opposing the proposition stated that: (a) examinations will give students bad memories of school, (b) examinations would cause many students to lose large amounts of sleep while studying, and (c) college students take enough exams already. 
Dependent Variables

Attitude. Attitudes toward the issue of requiring comprehensive examinations for graduation from college were measured on a standard set of four seven-point semantic differential-type scales (see Appendix C). The scales were anchored with the adjectives good-bad, valuable-worthless, desirable-undesirable, beneficial-harmful.

Message elaboration. Since issue involvement should motivate message elaboration (Petty \& Cacioppo, 1979), a second manipulation check of issue involvement consisted of a message elaboration scale (Reynolds, 1986; see Appendix C). The measure consists of seven-point likert items following twelve phrases, six of which represent cognitive effort, and six which represent a lack of cognitive effort. The twelve phrases completed the question "While reading the message were you:" (a) attempting to analyze the issues in the message, (b) not very attentive to the ideas, (c) deep in thought about the message, (d) unconcerned with the ideas, (e) extending a good deal of cognitive effort, (f) distracted by other thoughts not related to the message, ( $g$ ) not really exerting your mind, (h) doing your best to think about what was written, (i) reflecting on the implications of the arguments, (j) resting your mind, (k) searching your mind in response to the ideas, and (1) taking it easy. Responses to 
this scale provided a test of the assumption that high involvement motivates message elaboration. Analysis

The data were analyzed using a $2 \times 2 \times 3$ analysis of variance. Independent variables were issue involvement (high, low), quality of arguments (high supporting/low opposing, low supporting/high opposing), and majority position (for, against, none). The posttest measure of attitude was the dependent variable. The critical test of the hypothesis consisted of analyzing the interaction between argument quality, the majority position, and issue involvement on attitude shift. The level of significance for all analyses was set at .05 .

\section{Results}

\section{Scale Reliabilities}

Reliabilities for all scales were estimated by Cronbach's alpha and met or exceeded the traditional .80 criterion level. The attitude measure was reliable, alpha = .92. The scales measuring perceptions of argument quality for and against were each reliable, alpha $=.93$. The measure of involvement achieved reliability of .80 . Reliability for the scales measuring message elaboration was also substantial, alpha $=.86$. 
Manipulation Checks

Manipulations of argument quality were successful. For the arguments in favor of comprehensive examinations, high quality arguments were perceived as higher in quality $(M=$ 17.86) than were low quality arguments $(\underline{M}=12.47), \underline{F}(1,241)$ $=46.5, \underline{p}=.001, \underline{r}^{2}=.16$. The high quality arguments opposing the examinations were perceived as higher in quality $(M=20.47)$ than were the low quality arguments $(M=11.52)$, $\underline{E}(1,244)=127.9, \underline{p}=.001, \underline{r}^{2}=.34$. The manipulation of majority was not significantly correlated with either perceptions of argument quality in support of the proposition $(\underline{r}=.02, \mathrm{nsd})$ or perceptions of argument quality opposed to the proposition ( $\underline{r}=-.01$, nsd) .

The majority position induction was moderately successful. The majority was correctly perceived by 207 subjects (83 percent). There were 42 subjects who either responded incorrectly or did not respond to the item.

The manipulation of involvement was somewhat successful. The effect of the manipulation of involvement on the perception of involvement was significant, $\underline{E}(1,246)=3.94$, $\underline{p}<.05$, but was very weak, $\underline{\underline{r}}^{2}=.02$.

The manipulation of involvement had no significant effect on message elaboration, $\underline{F}(1,244)=.16$, nsd. However, when a tertiary split was performed on perceptions of involvement, it was found that subjects with increased 
perceptions of involvement elaborated more than subjects with lower perceptions of involvement, $\underline{E}(1,242)=18.67, \underline{p}=$ $.001, \underline{r}^{2}=.13$. Put another way, there was a significant, positive correlation between perceptions of involvement and message elaboration, $\underline{r}=.36(\mathrm{df}=244, \underline{p}=.001)$. Hypothesis

The hypothesis was not supported. The interaction between manipulation of involvement, argument quality and majority position was not significant, $\underline{E}(1,198)=.064$, nsd. There was a main effect for argument quality. When examinations were supported by high quality arguments and opposed by low quality arguments subjects were more likely to agree with the proposal $(\underline{M}=16.05)$ than when the proposal was opposed by high quality arguments and supported by low quality arguments $(M=10.96), \underline{E}(1,189)=37.81, \underline{p}=.001$. There was also a two-way interaction between message elaboration and argument quality. Increasing message elaboration was associated with less agreement with the proposition when low quality arguments supported exams and high quality arguments opposed exams. Increasing message elaboration was associated with increased agreement with the proposition when high quality arguments supported exams and low quality arguments opposed exams, $\underline{F}(1,189)=5.84, \mathrm{p}=$ .003 (see table 1 ). No other main effects or interactions attained significance (see tables 2a, 2b). 


\section{Discussion}

Hypothesis

The results of this study do not support the hypothesis that highly involved subjects are more likely to be influenced by the persuasive arguments process and low involved subjects are more likely to be influenced by the social comparison process. The predicted interaction between manipulation of involvement, argument quality, and majority position was not significant. In fact, the results of this study support the persuasive arguments process theory. The main effect for argument quality, leads to the conclusion that individuals are influenced by persuasive arguments and not by social comparison processes. Additional Findings

The failure to find a correlation between the manipulation of majority position and perceptions of argument quality would appear to conflict with the speculations of Boster and Mayer (1984) that it is impossible to manipulate majority position and argument quality separately. However, since the manipulation of majority was only somewhat successful, the claim that it is possible to manipulate majority position and argument quality separately cannot be substantiated.

The results fail to support Isenberg's (1986) prediction that high involvement fosters a social comparison process. 
In order to support Isenberg, the high involvement subjects would have had to shift their attitudes in the direction of the majority position. However, high involvement subjects' attitudes shifted in the direction of the high quality arguments, not in the direction of the majority position.

Although the manipulation of involvement had no significant effect on message elaboration, the weakness of the manipulation makes it impossible to argue against the documented link between involvement and message elaboration (Petty \& Cacioppo, 1979). Indeed, the moderately positive association obtained between perceptions of involvement and message elaboration supports the assumption of a relationship between involvement and message elaboration.

The combination of the relationship between involvement and message elaboratior, and the two-way interaction between message elaboration and argument quality on attitude, supports the findings of Petty and Cacioppo (1979). Increased involvement led to increased message elaboration. Increasing message elaboration was associated with increased persuasion for high quality arguments, and decreased persuasion for low quality arguments.

\section{Limitations}

Involvement. The manipulation of involvement had at best a weak, though significant impact on perceptions of 
involvement. Subjects in both the high involvement $(\mathbb{M}=$ 14.42) and low involvement $(M=13.30)$ conditions had mean involvement scores slightly above the midpoint of the scale, (Scale Range $=3-21$, Midpoint $=12$ ). This implies that even in low involvement conditions, subjects felt more than slightly involved. In fact, low involvement subjects had a bimodal distribution of involvement with the predominant mode $\underline{M O}=15)$ higher than the high involvement subjects' mode (므 =14). These two findings make it clear that the low involvement manipulation was not entirely successful in causing all low involvement condition subjects to feel low levels of involvement. It is possible that subjects did not believe that their opinions would be solicited about a policy proposal for the state of Georgia, and, hence were suspicious that the examinations were being considered for their own institution. A more credible manipulation of involvement is needed to better observe the effect of this variable.

Majority. A large number of subjects $(\mathbb{N}=42,17$ percent) misperceived the majority position or did not respond to the majority item. Evidently, the manipulation of the majority position could have been much stronger. It is possible that a stronger manipulation of majority position would have a significant effect on the results. If the majority position was difficult to perceive, low involvement 
subjects may have sought alternative heuristic cues on which to base their opinions.

A word count of the stimulus materials revealed that the high quality arguments may have been perceptibly longer than the low quality arguments. It is possible that low involvement subjects' opinions shifted on the basis of this cue. This argument length effect would mimic an argument quality effect.

Summary

In summary, the results of this study support a persuasive arguments process rather than a heuristic approach to explaining the choice shift phenomenon. However, the results may be an artifact of the limitations that have been discussed. 
Table 1

Means for Attitude Measure by Message

Elaboration and Argument Ouality

\begin{tabular}{ll}
\multicolumn{2}{c}{ Argument Quality } \\
Low Supporting/ & High Supporting/ \\
High Opposing & Low Opposing
\end{tabular}

High

9.35

16.74

$(n=31)$

$(n=39)$

Message

Elaboration

Moderate

10.97

18.39

$(n=38)$

$(n=31)$

Low

$$
\begin{aligned}
& 12.78 \\
& (n=27)
\end{aligned}
$$

13.61

$(n=41)$

Note. Scale Range $=4-28$. Higher means indicate increased agreement with the proposition for comprehensive examinations. 
Table $2 \mathrm{a}$

Means for Attitude Measure by Manipulation of Involvement, Majority Position, and Argument Ouality

Argument Quality = Low Supporting/High Opposing

Majority Position

For Against No Majority

$\begin{array}{ccccc} & \text { High } & \begin{array}{c}11.50 \\ (n=14)\end{array} & \begin{array}{c}10.00 \\ (n=18)\end{array} & \begin{array}{c}11.94 \\ (n=16)\end{array} \\ \text { Involvement } & \text { Low } & \begin{array}{c}11.18 \\ (n=17)\end{array} & \begin{array}{c}10.59 \\ (n=17)\end{array} & \begin{array}{c}11.00 \\ (n=16)\end{array}\end{array}$

Argument Quality = High Supporting/Low Opposing Majority Position

For Against No Majority

\begin{tabular}{ccccc} 
& High & 16.33 & 13.56 & 15.50 \\
Involvement & & $(n=18)$ & $(n=18)$ & $(n=18)$ \\
& \multirow{2}{*}{ Low } & $\begin{array}{l}17.33 \\
(n=18)\end{array}$ & $\begin{array}{l}16.71 \\
(n=21)\end{array}$ & $\begin{array}{l}17.32 \\
(n=19)\end{array}$
\end{tabular}

Note. Scale Range $=4-28$. Higher means indicate increased agreement with the proposition for comprehensive examinations. 
Table $2 \mathrm{~b}$

ANOVA table for Experiment 1

\begin{tabular}{|c|c|c|c|c|c|}
\hline & SUM OF & & $\begin{array}{l}\text { MEAN } \\
\text { SOIARF }\end{array}$ & & SIGNIE \\
\hline $\begin{array}{l}\text { SOURCE OF } \\
\text { VARIATION }\end{array}$ & & $\mathrm{DF}$ & SQUARE & $\mathrm{F}$ & \\
\hline MAIN EFFECTS & 1512.567 & 4 & 378.142 & 9.434 & .001 \\
\hline Inv. & 49.698 & 1 & 49.698 & 1.240 & .267 \\
\hline Maj. Position & 75.394 & 2 & 37.697 & .940 & .392 \\
\hline Arg. Qual. & 1376.952 & 1 & 1376.952 & 34.353 & .001 \\
\hline 2-WAY INTERACTIONS & 95.584 & 5 & 19.117 & .477 & .793 \\
\hline Inv. X Maj. Pos. & 27.106 & 2 & 13.553 & .338 & .714 \\
\hline Inv. X Arg. Qual. & 65.027 & 1 & 65.027 & 1.622 & .204 \\
\hline Maj. Pos. X Arg.Qua] & al. 3.889 & 2 & 1.944 & .049 & .953 \\
\hline 3-WAY INTERACTIONS & 5.111 & 2 & 2.556 & .064 & .938 \\
\hline $\begin{array}{l}\text { Inv. X Maj. Pos. X } \\
\text { Ang. Qual. }\end{array}$ & 5.111 & 2 & 2.556 & .064 & .938 \\
\hline EXPLAINED & 1613.263 & 11 & 146.660 & 3.659 & .001 \\
\hline RESIDUAL & 7936.361 & 198 & 40.083 & & \\
\hline TOTAL & 9549.624 & 209 & 45.69 & & \\
\hline
\end{tabular}




\section{Chapter 4}

Experiment 2

A second study was designed to test the hypothesis after attempting to correct the limitations discussed regarding Experiment 1. The manipulations of involvement and majority were improved in an effort to find the predicted involvement, majority position, argument quality interaction on attitude. The hypothesis remains the same: In low CPD situations, low issue involved subjects should be more influenced by the majority, and high involved subjects should be more influenced by the quality of the arguments.

\section{Methods}

Subjects

Subjects were volunteer undergraduate students at San Jose State University and California Polytechnic University at San Luis Obispo. Two hundred sixty-four subjects participated in the study. Six conditions out of twelve were unequally represented initially due to faulty assembling of the questionnaires. Subsequently, the proportion of questionnaires distributed from the under represented conditions was increased at the expense of randomization in order to provide approximately equal cell sizes. Nine subjects were removed from the analysis due to incorrectly completing the questionnaire. The total number of completed responses was $\underline{N}=255$. 


\section{Procectures}

The same attitude issue, comprehensive examinations for graduation from college, was used as in Experiment 1. The twelve booklet versions followed the same format as in Experiment 1, with one exception. Since the order of the manipulation check items and the message elaboration scale had no effect on attitude change, only three of the possible six scale orders were used in randomizing across conditions. Independent Variables

Issue involvement. The issue involvement manipulation was improved by changing the low involvement manipulation to be more credible. The low issue involvement condition contained a script in which comprehensive examinations were being discussed for possible implementation at several private colleges in northern California in the year 2000. In the high issue involvement condition the script contained the same manipulation as in Experiment 1 (possible implementation of comprehensive examinations at the subject's institution the following semester).

In an effort to increase perceptions of high and low involvement, subjects were informed that they were being asked to read the transcript and respond to it in an effort to gather the opinions of students who could be affected in many ways (will not be affected in any way) if the proposal 
was accepted (see Appendix D). The same manipulation check was used as in Experiment 1 (see Appendix C) .

Majority. The majority manipulation was improved by having five out of six group members in favor of (opposed to) an extreme position on the selected topic (see Appendix D) . The sixth member was opposed to (in favor of) the extreme position. The script consisted of an instructor interrupting a group discussion to poll the attitudes of the group members. The first and second speakers again offered strong (weak) arguments in support of their opposing positions. In the majority conditions the remaining four speakers indicated agreement with the first speaker, but offered no new arguments. In the no majority conditions the remaining four speakers alternated in their support of either the first or second speaker, and again offered no new arguments. In an effort to increase the perceptions of majority position, the instructor provided a summation by saying, "Alright, I see that after discussing the issue, the majority of the group is in favor of (opposed to) (there is no majority in favor of or opposed to) requiring students to pass a comprehensive examination to graduate." The same manipulation check was used as in Experiment 1 (see Appendix C) .

Argument quality. Argument quality was manipulated in the same way as in Experiment 1. In an effort to increase the effect of the manipulation of argument quality in favor 
of the proposition, three new strong arguments and two new weak arguments were used from Petty \& Cacioppo's (1979) study which used the topic of comprehensive examinations (see Appendix D) .

The new strong arguments in favor of the examinations were: (a) universities with the exams attract larger and better known corporations to recruit students for jobs, (b) average starting salaries are better for graduates of schools with the exams, and (c) a tuition increase would be avoided because the state legislature would increase funding if the exams are instituted. The new weak arguments in favor of the examinations stated that (a) gracuate students are complaining that since they have to take exams, undergraduates should have to take them also, and (b) comprehensive exams are a tradition dating back to the ancient Greeks.

All other arguments remained the same as in Experiment 1. The manipulation check used in Experiment 2 was the same as was used in Experiment 1 (see Appendix C) . Dependent Variables

Attitude. Attitudes toward the issue of requiring comprehensive examinations for graduation from college were measured on the same set of four seven-point semantic differential-type scales. The scales were again anchored 
with the adjectives good-bad, valuable-worthless, desirableundesirable, beneficial-harmful (see Appendix C) .

Message elaboration. Message elaboration was again measured to test the assumption that increasing involvement motivates message elaboration. The same scales were used as in Experiment 1 (see Appendix C).

\section{Results}

Scale Reliabilities

Reliabilities for all scales were again substantial. The reliability of the attitude measure was computed at alpha .93. The scales measuring perceptions of argument quality for and against were also reliable, alpha $=.93$, and alpha $=$ .92, respectively. The reliability of the measure for involvement was .80 . The elaboration scales attained a reliability of .86 . Manipulation Checks

Manipulations of argument quality were again successful. High quality arguments in favor of examinations were judged to be higher in quality $(M=19.07)$ than were the low quality arguments $(\underline{M}=12.80), \underline{E}(1,252)=79.9, \underline{p}<.001, \underline{\underline{r}}^{2}=.24$. Arguments opposing the examinations were judged higher in quality in the high quality condition $(\underline{M}=19.38)$ than in the low quality condition $(\underline{M}=11.23), \underline{E}(1,251)=151.04, \underline{p}<$ $.001, \underline{r}^{2}=.38$. The manipulation of majority was not significantly correlated with perceptions of argument quality 
in support of the proposition $(\underline{r}=.04, \mathrm{nsd})$ or perceptions of argument quality against the proposition $(\underline{r}=.08$, nsd). The majority position induction was somewhat more successful in Experiment 2. The majority was correctly perceived by 236 subjects (92.5 percent). Nineteen subjects either responded incorrectly or did not complete the item. The manipulation of involvement was also more successful in Experiment 2. The effect of the manipulation of involvement on the perception of involvement was significant, $\underline{E}(1,253)=17.26, \underline{p}<.001, \underline{r}^{2}=.06$.

The effect of manipulation of involvement on elaboration was again non-significant. However, the effect was in the predicted direction, $\underline{E}(1,242)=3.10, \underline{p}=.08$. As in Experiment 1, a tertiary split was performed on subjects' perceptions of involvement. For Experiment 2, subjects' perceptions of involvement were not significantly related to elaboration, $\underline{E}(1,240)=2.16, \underline{p}=.12$. The correlation between perceptions of involvement and elaboration was significant, $\underline{r}=.25$ ' $\mathcal{X} F=220, \underline{p}=.001$ ). Hypothesis

The results again failed to support the hypothesis. The interaction between manipulation of involvement, argument quality and majority position was non-significant, $\underline{F}(1,220)=.60$, nsd. The main effect for argument quality was again significant, $\underline{E}(1,220)=9.95, \underline{p}=.002$. No other 
main effects or interactions attained significance (see tables $3 a$ and $3 b)$.

\section{Discussion}

Hypothesis

The hypothesis regarding the likelihood that highly involved subjects would be influenced by argument quality (i.e., persuasive arguments processes) and low involved subjects would be influenced by the majority position (i.e., social comparison processes) failed to receive support. The predicted interaction of manipulation of involvement by argument quality by majority position on attitude was not significant. Again, the results of Experiment 2 support the persuasive arguments theory. The main effect for argument quality supports the assumption that individuals are influenced by persuasive arguments rather than by social comparison.

Additional Findings

The failure to find a correlation between the manipulation of majority position and perceptions of argument quality would again appear to conflict with Boster and Mayer's (1984) reasoning regarding an inability to manipulate these two variables separately. While the manipulation of majority position was improved over Experiment 1, it would still be unwise to claim that separate manipulations of majority position and argument quality are possible. At 
best, it appears that the relationship between majority position and argument quality is worthy of further examination.

Isenberg's (1986) prediction of a positive relationship between high involvement and social comparison processes did not receive support from the results of Experiment 2. High involvement subjects were more likely to engage in persuasive arguments processes than in social comparison processes, as evidenced by attitude shifts in the direction of the higher quality arguments rather than shifts toward the majority position.

As in Experiment 1, the manipulation of involvement had a non-significant effect on elaboration. A tertiary split on perceptions of involvement and subsequent analysis, revealed no significant effect for perceptions of involvement on elaboration. Although cell means were in the predicted direction, these non-significant findings cannot be taken as support of a relationship between involvement and elaboration (Petty \& Cacioppo, 1979). However, the correlation between perceptions of involvement and elaboration can be taken as limited support for an involvement/elaboration link.

\section{Limitations}

Involvement. A limitation of Experiment 2 may again be the manipulation of involvement. While the manipulation attained significance, the effect size was again weak, $\underline{\underline{r}}^{2}=$ 
.06. It is unknown what impact a stronger involvement effect would have on the analysis.

Majority. The weakness of the majority manipulation is, again, a possible limitation. Although there was a 10 percent improvement on majority perception over Experiment 1, a 7.5 percent attrition rate seems quite high for one variable. In Boster and Mayer's (1984) study, 11 percent of the subjects responded incorrectly or did not respond to the manipulation check on majority. Apparently, subjects have difficulty perceiving the majority in script manipulations like the ones used here and by Boster and Mayer. The effect of this difficulty in majority perception on social comparison processes is not known. It is possible that in actual group interaction subjects would have no trouble perceiving the majority position, and social comparison processes might be observed. 
Table $3 a$

Means for Attitude Measure by Manipulation

of Involvement, Majority Position, and Argument Quality

Argument Quality = Low Supporting/High Opposing

Majority Position

For Against No Majority

$\begin{array}{ccccc} & \text { High } & \begin{array}{c}13.36 \\ (\mathrm{n}=22)\end{array} & \begin{array}{c}16.00 \\ (\mathrm{n}=23)\end{array} & \begin{array}{c}12.61 \\ (\mathrm{n}=18)\end{array} \\ \text { Involvement } & & & & \\ & \text { Low } & \begin{array}{l}13.60 \\ (\mathrm{n}=20)\end{array} & \begin{array}{c}14.11 \\ (\mathrm{n}=18)\end{array} & \begin{array}{c}15.63 \\ (\mathrm{n}=16)\end{array}\end{array}$

Argument Quality = High Supporting/Low Opposing

Majority Position

For Against No Majority

Involvement

\begin{tabular}{cccc}
\multicolumn{4}{c}{ Majority Position } \\
High & For & Against & No Majority \\
& $\begin{array}{c}18.59 \\
(n=17)\end{array}$ & $\begin{array}{c}17.25 \\
(n=20)\end{array}$ & $\begin{array}{c}16.20 \\
(n=20)\end{array}$ \\
Low & $\begin{array}{c}16.05 \\
(n=17)\end{array}$ & $\begin{array}{c}16.46 \\
(n=20)\end{array}$ & $\begin{array}{c}16.71 \\
(n=20)\end{array}$
\end{tabular}

Note. Scale Range $=4-28$. Higher means indicate increased agreement with the proposition for comprehensive examinations. 
Table 3b

ANOVA Table for Experiment 1

SOURCE OF

VARIATION

MAIN EFEECTS

Inv.

Maj. Position

Arg. Qual.

$\begin{array}{rrrrr}\text { SUM OF } & & \text { MEAN } & & \text { SIGNIF } \\ \text { SQUARES } & \text { DF } & \text { SQUARE } & F & \text { OF F }\end{array}$

$\begin{array}{lllll}424.446 \quad 4 & 106.112 & 2.726 & .030\end{array}$

$\begin{array}{lllll}6.407 & 1 & 6.407 & .165 & .685\end{array}$

$\begin{array}{lllll}27.967 & 2 & 13.984 & .359 & .699\end{array}$

$\begin{array}{lllll}387.257 & 1 & 387.257 & 9.948 & .002\end{array}$

$\begin{array}{llllll}\text { 2-WAY INTERACTIONS } & 174.176 & 5 & 34.835 & .895 & .485\end{array}$ Inv. X Maj. Pos.

Inv. X Arg. Qual.

105.116

23.309

Maj. Pos. X Arg. Qual. 43.870

$2 \quad 52.558$

23.309

21.935

1.350

.599

.563

.261

.440

2

46.780

46.780

2
2

23.390

23.390

.601

.601

.549

Inv. X Maj. Pos.

$X$ Arg. Qual.
EXPLAINED

RESIDUAL

TOTAL $\begin{array}{lllll}645.401 & 11 & 58.673 & 1.507 & .130\end{array}$

$8564.500 \quad 220 \quad 38.930$

$9209.931 \quad 231 \quad 39.870$ 


\section{Chapter 5}

General Discussion: Experiment 1 and Experiment 2 Hypothesis

The findings, though limited, supported a persuasive arguments process. Results provided no support for the hypothesis that involvement would discriminate between situations in which persuasive arguments processes would operate and those in which social comparison processes would operate.

\section{Additional Findings}

As a result of the problems experienced in manipulating the majority position, it is impossible to sustain or reject with confidence the claim of Boster and Mayer (1984) that majority position and argument quality cannot be manipulated separately. If separate manipulation of majority position and argument quality is possible, it may be that Boster and Mayer's finding of a confounding of these two variables was a result of the use of a particular topic.

Neither Experiment 1, nor Experiment 2 found any support for Isenberg's (1986) assumption that involvement would foster a social comparison process. On the contrary, persuasive arguments processes were more prevalent regardless of the level of involvement. 


\section{Limitations}

\section{Involvement}

The manipulations of involvement in the two experiments reported were apparently not sufficient. Although the manipulations of involvement had a significant effect on perceptions of involvement in both Experiment 1 and

Experiment 2, the effect sizes in both experiments $\underline{r}^{2}=.02$, $\underline{r}^{2}=.06$ respectively) were very weak. It is possible that the argument quality effects, which had effect sizes of .16 and .34 in Experiment 1 and effect sizes of .24 and .38 in Experiment 2, masked any other possible effects. This may also explain the lack of a majority effect finding. Majority

The manipulations of majority were somewhat successful for Experiment 1 (majority position correctly perceived by 83 percent of subjects) and Experiment 2 (majority position correctly perceived by 92.5 percent of the subjects). Nevertheless, majority position neither produced a main effect, nor contributed to any interaction effects. Again, it may be that any possible effect was masked by the argument quality effect.

Issue

Finally, the issue used in these two studies may have certain characteristics which could affect decision outcomes. 
Two of these characteristics may be the scope of the outcome, and the consequences of choosing a side.

The scope of the outcome is one variable which was not examined in the present research. The scope of the outcome refers to which individuals, if any, will be affected by the decision that is made. Although some researchers (Iaughlin \& Earley, 1982) have studied differences in decisions made for self, friend and stranger, their research used hypothetical choice dilemma itens. On attitude issues for which discussed alternatives could procuce realistic outcomes, group processes may be significantly impacted by which individuals the outcome will affect (e.g., some group members; all group members; no group members, but some others) .

The consequences of choosing a side may have an impact on group processes as well. Research by Petty and Cacioppo (1979) has shown that arguments in favor of comprehensive examinations are counterattitudinal for most college students. However, at an institution where undergraduates are convinced that they are receiving a high quality education, students may not feel threatened by the examinations and may welcome the opportunity to prove themselves. In the present experiments, the attitudinal mean of the combined sarmples on the issue of the examinations was 14.5 (Scale Range $=4-28$, Midpoint $=16$ ). This moderate attitude score could imply feelings of neutrality. Students 
who may doubt the quality of their education could be placed in a double bind by the issue of requiring comprehensive examinations for graduation. Support of the proposal could result in implementation of the examinations which the student may be fearful of failing. However, opposing the examinations would imply doubt of the quality of one's own education, which the individual may not be willing to admit. Thus, the subject could be effectively forced into neutrality. Neutral indivicuals have moderate to high salience for an issue, and "have knowledge regarding both sides of the issue (but are ambivalent)," (Hylton \& Lashbrook, 1972, p. 108). Hence, neutral subjects are likely to behave quite differently from favorable, unfavorable, or apathetic individuals, and may be harder to persuade. Therefore, the consequences of choosing a side on a particular issue in a given population could have an unspecified effect on a choice shift.

\section{Euture Research}

In the future, researchers should take into consideration the limitations encountered by the present experiments. Manipulations of involvement should be sufficient to generate larger effect sizes. Manipulations of majority position in studies which use a script as the stimulus item should be aware that the type of manipulation 
used here and by Boster and Mayer (1984) is apparently difficult for subjects to perceive.

Another interesting avenue for future research to explore is whether the distinction between favorable, unfavorable, apathetic, and neutral individuals is useful for predicting outcomes in groups which engage in choice shift processes. Lashbrook, Hylton, and Findley (Hylton, Findley, \& Lashbrook, 1987, 1988; Lashbrook \& Hylton, 1985; Lashbrook, Hylton, \& Findley, 1986) have developed an instrument which provides an efficient means of classifying individuals as favorable, unfavorable, apathetic or neutral according to their response on two scales. The first scale is a standard Likert type scale (strongly agree-strongly disagree) following a statement about the issue. The second scale follows a question about the importance of the issue and is anchored with the adjectives very important-very unimportant.

A subject with a moderate attitude score and a low importance score is classified as apathetic. A subject with a moderate attitude score and a high importance score is classified as neutral. It is possible that social comparison processes are most prevalent among apathetic indivicuals, while neutral individuals may be more susceptible to persuasive arguments processes.

Finally, future research may wish to examine some of the issue-related variables discussed herein. Two of these 
issue-related variables are the scope of the outcome, or which individuals will be affected by the decision, and the consequences of choosing a side for a particular issue. 
References 
Apsler, R., \& Sears, D. O. (1968). Warning, personal involvement, and attitude change. Journal of Personality and Social Psychology, 2, 162-166.

Axsom, D., Yates, S., \& Chaiken, S. (1987). Audience response as heuristic cue in persuasion. Journal of Personality and Social Psychology, 53, 30-40.

Boster, F. J., \& Mayer, M. (1984). Choice shifts: Argument qualities or social comparisons. In R. N. Bostrom \& B. U. Westley (Eds.), Communication Yearbook: Vol. 8 (pp.393-410). Beverly Hills: Sage.

Burnstein, E., \& Vinokur, A. (1973). Testing two classes of theories about group induced shifts in individual choice. Journal of Experimental Social Psychology, 9, 123-137.

Burnstein, E., \& Vinokur, A. (1975). What a person thinks upon learning he has chosen differently from others: Nice evidence for the persuasive arguments explanation of choice shifts. Joumal of Experimental Social Psychology, 11, $412-426$.

Burnstein, E., Vinokur, A., \& Trope, Y. (1973). Interpersonal comparison versus persuasive argumentation: A more direct test of alternative explanations for group induced shifts in individual choice. Journal of Experimental Social Psychology, 9, 236-245.

Chaiken, S. (1980). Heuristic versus systematic information processing and the use of source versus message cues in persuasion. Journal of Personality and Social Psychology, $39,752-756$.

Chaiken, S., \& Eagly, A. H. (1983). Communication modality as a deteminant of persuasion: The role of communicator salience. Journal of Personality and Social Psychology, 45, 241-256. 
Cotton, J. L., \& Baron, R. S. (1980). Anonymity, persuasive arguments, and choice shifts. Social Psychology ouarterly, 43, 391-404.

Granberg, D. (1982). Social judgment theory. In M. Burgoon (Ed.), Communication Yearbook: Vol. 6 (pp. 304-329). Beverly Hills: Sage.

Hocking, J., Margreiter, D., \& Hylton, C. (1977). Intraaudience effects: A field test. Human Communication Research, 3, 243-249.

Hylton, C. (1971). Intra-audience effects: Observable audience response. Journal of Communication, 21, 253-265.

Hylton, C., Findley, P., \& Lashbrook, W. (1987, May). Iinking computer simulation to employ attitude research. Paper presented at the meeting of the Western Speech Communication Association, Salt Lake City, UT.

Hylton, C., Findley, P., \& Lashbrook, W. (1988, May). CrossValidating customers' concerns in order to improve communication: Surveys vs, focus groups. Paper presented at the meeting of the Western Speech Communication Association, San Diego, CA.

Hylton, C., \& Lashbrook, W. B. (1972). Apathetic and neutral audiences: A computer simulation and validation. Speech Monographs, 39, 105-113.

Isenberg, D. J. (1986). Group polarization: A critical review and meta-analysis. Joumal of Personality and Social Psychology, 50, 1141-1151.

Kellermann, K., \& Jarboe, S. (1987). Conservatism in judgment: Is the risky shift-ee really risky, really? In M. L. McLaughlin (Ed.), Communication Yearbook: Vol, 10 (pp. 259-282). Beverly Hills: Sage. 
Kiesler, C., Collins, B., \& Miller, N. (1969). Attitude change. New York: Wiley.

Kogan, N., \& Wallach, M. A. (1964). Risk taking: A study in cognition and personality. New York: Holt, Rinehart \& Winston.

Lashbrook, W., \& Hylton, C. (1985, May) - Utility company A: An image study. Paper presented at the meeting of the Western Speech Communication Association, Fresno, CA.

Lashbrook, W., Hylton, C., \& Findley, P. (1986, May). Applying computer simulation to design and test message strategies for business organizations. Paper presented at the meeting of the Western Speech Communication Association, Tucson, AZ.

Laughlin, P. R., \& Earley, P. C. (1982). Social combination models, persuasive arguments theory, social comparison theory, and choice shift. Journal of Personality and Secial Psychology, 42, 273-280.

March, S. A., \& Reynolds, R. A. (1988, May). The effects of involvement and quality of majority or minority arguments on attitude shift in small groups. Paper presented at the meeting of the International Commication Association, New Orleans, IA.

McLachlan, A. (1986). The effects of two forms of decision reappraisal on the perception of pertinent arguments. British Journal of Social Esychology, 25, 129-138.

Meyers, R. A., \& Seibold, D. R. (1988, May). Testing persuasive argument theory's predictor model: Alternative interactional accounts of group argument and influence. Paper presented at the meeting of the International Cormunication Association, New Orleans, LA. 
Miller, N. (1978). A questionnaire in search of a theory. In L. Berkowitz (Ed.), Group processes (pp. 301-312). New York: Academic Press.

Miller, N., Maruyama, G., Beaber, R. J., \& Valone, K. (1976). Speed of speech and persuasion. Journal of Personality and Social Psychology, 34, 615-625.

Myers, D. G., Bruggink, J. B., Kersting, R. C., \& Schlosser, B. A. (1980). Does learning others' opinions change one's opinions? Personality and Social Psychology Bulletin, 6, 253-260.

Myers, D. G., \& Lanm, H. (1976). The group polarization phenomenon. Psychological Bulletin, 83, 602-627.

Myers, D. G., Wojcicki, S. B., \& Aardema, G. C. (1977) . Attitude comparison: Is there ever a bandwagon effect? Journal of Applied Social Psychology, 1, 341-347.

Olds, A. S. (1980). The effects of sequentially varied observable audience response on attraction and source credibility in a small group. Unpublished master's thesis, San Jose State University, San Jose, CA.

Petty, R. E., \& Cacioppo, J. T. (1979). Issue involvement can increase or decrease persuasion by enhancing messagerelevant cognitive responses. Joumal of Personality and Social Psychology, 37, 1915-1926.

Petty, R. E., Cacioppo, J. T., \& Goldman, R. (1981). Personal involvement as a deteminant of argument-based persuasion. Journal of Personality and Social Psychology, 41, 847-855.

Reynolds, R. A. (1986). The effects of cognitive elaboration, valid arguments, evidence, and message style in persuasive discourse. Unpublished doctoral dissertation, Michigan State University. 
Sherif, C. W., Kelly, M., Rodgers, H. L., Jr., Sarup, G., \& Tittler, B. I. (1973). Personal involvement, social judgment, and action. Joumal of Personality and Social Psychology, 27, 311-328.

Sherif, M., \& Hovland, C. I. (1961). Social judgment:

Assimilation and contrast effects in communication and attitude change. New Haven, CT: Yale University.

Sherif, M., \& Sherif, C. W. (1967). Attitude as the indivicual's own categories: The social judgmentinvolvement approach to attitude and attitude change. In M. Sherif \& C. W. Sherif (Eds.), Attitude, egoinvolvement, and change (pp. 105-139). New York: John Wiley \& Sons, Inc.

Stoner, J. A. F. (1968). Risky and cautious shifts in group decisions: The influence of widely held values. Journal of Experimental Social Psychology, 4, 442-459.

Vinokur, A., \& Burnstein, E. (1974). Effects of partially shared persuasive arguments on group induced shifts: A group problem solving approach. Journal of Personality and Social Psychology, 29, 305-315.

Vinokur, A., \& Burnstein, E. (1978). Depolarization of attitudes in groups. Journal of Personality and Social Psychology, 36, 872-885.

Whitney, J. C. \& Smith, R. A. (1983). Effects of group cohesiveness on attitude polarization and the acquisition of knowledge in a strategic planning context. Journal of Marketing Research, 20, 167-176. 


\section{APPENDICES}


Appendix A

Pilot Test Booklets 
Please respond to the following statements by placing an " $x$ " in the space which best represents your attitude.

Requiring employees to provide their employers with the results of a drug detection test is: Good : : Bad

I belleve that eliminating social security taxes and requiring employees to provide proof of a personal retirement plan is: Worthless :_______: Valuable

I feel that requiring students to carpool to the university, or else park at off-campus sites and shuttle to campus is: Beneficial __:_______________ Harmful

I think that requiring employees to provide their employers with the results of a drug detection test is: Harmful :____________ : Beneficial

I feel that requiring students to carpool to the university, or else park at off-campus sites and shuttle to campus is:

Undesirable : _____ : Desirable

I belleve that requiring employees to provide their employers with the results of a drug detection test is: Valuable :_______________: Worthless

Eliminating social security taxes and requiring employees to provide proof of a personal retirement plan is:

$$
\mathrm{Bad} \_ \text {_________________ Good }
$$

I feel that requiring students to carpool to the university, or else park at off-campus sites and shuttle to campus is: Worthless : : : : : : : : Valuable

I feel that requiring employees to provide their employers with the results of a drug detection test is:

Undesirable : $:$ : : : : : : : : Desirable

I think that eliminating social security taxes and requiring employees to provide proof of a personal retirement plan is: Beneficial ___________________ Harmful

Requiring students to carpool to the university, or else park at offcampus sites and shuttle to campus is: Bad : : Good

I feel that eliminating social security taxes and requiring employees to provide proof of a personal retirement plan is:

Desirable

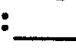
: : : : : : Undesirable 
Please respond to the following scales.

"All employees should be required to provide the results of a drug detection test to their employers."

The preceeding policy is being discussed for possible implementation in the state of New York within the next five years.

How important is this issue to you? Very Important :______

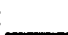
:__ Not at all Important

To what extent do you expect this issue to have significant consequences for your life?

Very Significant : : :_____ Not at all Significant

What level of personal meaning does this issue have for you? Not at all Meaningful ____________________________ Very Meaningful

"All college students should be required to carpool in order to park in university garages, or else park at off-campus sites and shuttle to campus."

The preceeding policy is being discussed for possible implementation at San Jose State University in Fall 1988.

How important is this issue to you?

Not at all Important __ :__________________ Very Important

To what extent do you expect this issue to have significant consequences for your life?

Very Significant :

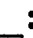
Not at all Significant

What level of personal meaning does this issue have for you? Not at all Meaningful ________________________ Very Meaningful

"Social security taxes should be eliminated and all employees should be required to provide proof of a personal retirement plan."

The preceeding policy is being discussed for possible implementation in Canada within the next ten years.

How important is this issue to you?

Not at all Important :________: :_____ Very Important

To what extent do you expect this issue to have significant consequences for your life? Not at all Significant :__: : : Very Significant

What level of personal meaning does this issue have for you? Very Meaningful _ : _ _ : _ : : _ : Not at all Meaningful 
Please respond to the following scales.

"All employees should be required to provide the results of a drug detection test to their employers."

The preceeding policy is being discussed for possible implementation in the state of California within the next year.

How important is this issue to you? very Important __ :__ : _ : : _________ Not at all Important

To what extent do you expect this issue to have significant consequences for your life?

Very Significant _____________________ Not at all Significant

What level of personal meaning does this issue have for you? Not at all Meaningful _______________________ Very Meaningful

"All college students should be required to carpool in order to park in university garages, or else park at off-campus sites and shuttle to campus."

The preceeding policy is being discussed for possible implementation in the state of New York in Fall, 1990.

How important is this issue to you?

Not at all Important ____________________ Very Important

To what extent do you expect this issue to have significant consequences for your life?

Very Significant _____________________ Not at all Significant

What level of personal meaning does this issue have for you? Not at all Meaningful _______________________ ____ Very Meaningful

"Social security taxes should be eliminated and all employees should be required to provide proof of a personal retirement plan."

The preceeding policy is being discussed for possible implementation in the United States next year.

How important is this issue to you? Not at all Important _______________________ Very Important

To what extent do you expect this issue to have significant consequences for your life?

Not at all Significant 11 . Very Significant

What level of personal meaning does this issue have for you? Very Meaningful Not at all Meaningful 
Below are some arguments sets supporting various positions on several topics. Please rate the quality of the arguments on the scales provided. Please rate the arguments in terms of quality, regardless of whether you agree or disagree with the position taken.

Employees should be required to provide employers with the results of a drug detection test because there are no jobs where the safety of the employee, employer, or public could not be compromised by employee drug usage. Productivity would also be increased on the fob through the elimination of drugs. With the knowledge of drug use, employers could also help in rehabilitation.

Reasonable Unconvincing

Persuasive Weak

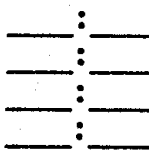
::- $: \square:-$ Unreasonable Convincing Lacking in Persuasiveness Strong

Students should be required to carpool in order to park in university garages, or else park at off-campus sites and shuttle to campus because it will force people to spend time together and help them to make friends. Riding in a carpool will also make students more responsible. In addition, carpooling will help reduce the smog around San Jose.

Strong
Convincing
Unreasonable $\square$
Persuasive $\square$

Social security taxes should be eliminated and employees should be required to provide proof of a personal retirement plan because the social security system is inefficient and more money could be provided for retirement by simply placing the same amount of money in a bank account. As the system stands there won't be enough money to provide retirement benefits for this generation. This policy would also encourage companies to provide competitive retirement plans which would benefit the employees.

Persuasive
Strong
Reasonable
Unconvincing

Employees should not be required to provide their employers with the results of a drug detection test because the test might hurt people. Also, so many people do drugs that you could seriously deplete the work force. Besides, you ought to be able to tell by the way a person looks whether or not they do drugs.

Reasonable

Persuasive Weak Unconvincing

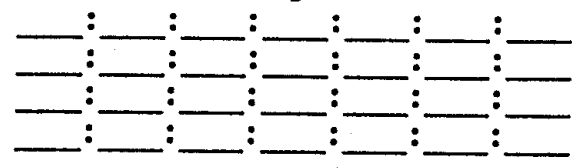
Unreasonable Lacking in Persuasiveness Strong Convincing 
Students should not be required to carpool in order to park in university garages, or else park at off-campus sites and shuttle to campus because such a policy infringes on personal freedom. It would be almost impossible to match schedules with people so that you could ride together. It would also be difficult to find people who live nearby to carpool with and would discriminate against those who don't live near other students.

Persuasive Strong Unconvincing

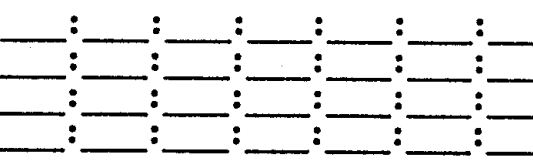
Lacking in Persuasiveness Reasonable Weak Convincing Unreasonable

Social security taxes should not be eliminated and employees required to provide proof of a personal retirement plan because people don't really need the extra money in their paycheck. Social security is good enough the way it is. The government needs the jobs provided by the current system. Unconvincing Persuastve Weak

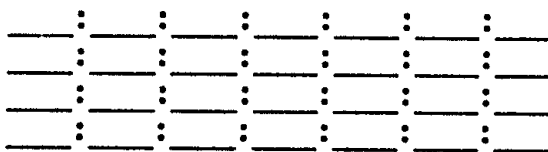

Convincing Reasonable Lacking in Persuasiveness Strong 
Please respond to the following statements by placing an " $x$ " in the space which best represents your attitude.

Requiring employees and students to provide their employers and/or schools with the results of an AIDS detection test is: Good :___________________ Bad

I believe that requiring comprehensive examinations for graduation from college is:

Valuable : ______________ Worthless

I think that adding $\$ 50.00$ to registration fees in order to defray parking costs and eliminate the need for parking fee increases is: Beneficial :_ HarmfuI

I feel that requiring comprehensive examinations for graduation from college is:

Undesirable _ ______________ Desirable

I believe that adding $\$ 50.00$ to registration fees in order to defray parking costs and eliminate the need for parking fee increases is: Bad __________________ Good

I think that requiring employees and students to provide their employers and/or schools with the results of an AIDS detection test is:

Desirable :________: :__ : Undesirable

Requiring comprehensive examinations for graduation from college is: Good : __ : : Bad

I feel that adding $\$ 50.00$ to registration fees in order to defray parking costs and eliminate the need for parking fee increases is: Undesirable :_____ : :_____: Desirable

I belleve that adding $\$ 50.00$ to registration fees in order to defray parking costs and eliminate the need for parking fee increases is: Worthless :______________: Valuable

I think that requiring employees and students to provide their employers and/or schools with the results of an AIDS detection test is:

Beneficial :________________ Harmful

I think that requiring comprehensive examinations for graduation from college is:

Harmful :________________ Beneficial

I believe that requiring employees and students to provide their employers and/or schools with the results of an AIDS detection test is: valuable :_ Worthless 
Please respond to the following scales.

"All employees should be required to provide the results of an AIDS detection test to their employers and/or schools."

The preceeding policy is being discussed for possible implementation in the state of California within the next year.

How imporcant is this issue to you? Very Important : : : : : : Not at all Important

To what extent do you expect this issue to have significant consequences for your life?

Very Significant ::___________: Not at all Significant

What level of personal meaning does this issue have for you? Not at all Meaningful : :_______ : : Very Meaningful

"All college students sinuld be required to take comprehensive examinations in order to qualify for graduation from college." The preceeding policy is being discussed for possible implementation in the state of New York in Fall, 1990.

How important is this issue to you? Not at a.l1 Important _________________________ very Important

To what extent do you expect this issue to have significant consequences for your life?

Very Significant : :

What level of personal meaning does this issue have for you? Not at all Meaningful : -__. :___. Very Meaningful

"An additional $\$ 50.00$ should be added to registration fees to defray parking costs and eliminate the need to raise parking fees."

The preceeding policy is being discussed for possible implementation at San Jose State University for Eall, 1988.

How important is this issue to you?

Not at all Important $: \quad: \quad: \quad:$ :______ Very Important

To what extent do you expect this issue to have significant consequences for your life? Not at all Significant _______________________ Very Significant

What level of personal meaning does this issue have for you? Very Meaningful - __________ : : : Not at all Meaningful 
Please respond to the following scales.

"All employees should be required to provide the results of an AIDS detection test to their employers and/or schools." The preceeding policy is being discussed for possible implementation in the state of New York within the next five years.

How important is this issue to you? Very Important : Not at all Important

To what extent do you expect this issue to have significant consequences for your life?

Very Significant : :_________ : Not at all Significant

What level of personal meaning does this issue have for you? Not at all Meaningful : : Very Meaningful

"All college students should be required to take comprehensive examinations in order to qualify for graduation from college." The preceeding policy is being discussed for possible implementation at San Jose State University in Fall, 1988.

How important is this issue to you?

Not at all Important _______________________ Very Important

To what extent do you expect this issue to have significant consequences for your life?

Very Significant ___ :________ Not at al.1 Significant

What level of personal meaning does this issue have for you? Not at all Meaningful : :__ : :___ Very Meaningful

"An additional $\$ 50.00$ should be added to registration fees to defray parking costs and eliminate the need to raise parking fees." The preceeding policy is being discussed for possible implementation in the state of New York for Fall, 1990.

How important is this issue to you?

Not at all Important $: \quad: \quad: \quad:$ :________ Very Important

To what extent do you expect this issue to have significant consequences for your life?

Not at all Significant _______________________ Very Significant

What level of personal meaning does this issue have for you? Very Meaningful : : ___ : _ : Not at all Meaningful 
Below are some arguments sets supporting various positions on several toplcs. Please rate the quality of the arguments on the scales provided. Please rate the arguments in terms of quality, regardless of whether you agree or disagree with the position taken.

Employees and students should be required to provide employers and/or schools with the results of an AIDS detection test because every individual has a right to know any disease that he/she may be exposed to. Testing would provide data on the spread of the disease which would be helpful to those trying to develop a cure. Additionally, testing would help employers and schools to provide counseling for AIDS victims.

Reasonable Unconvincing

Persuasive Weak

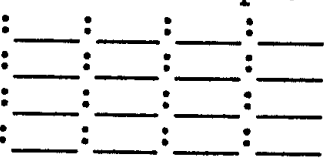
Unreasonable Convincing Lacking in Persuasiveness Strong

Comprehensive examinations should be a requirement for graduation from college because college students have it too easy right now. A comprehensive examination will let the student know if he/she is any good. Also, testing builds character. Unreasonable Persuastve

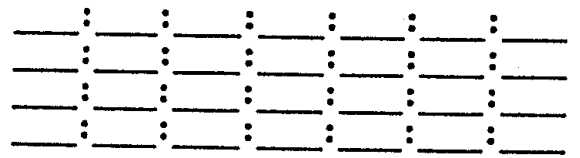
Weak Unconvincing Reasonable Lacking in Persuasiveness

A $\$ 50.00$ fee should be added to registration fees to defray parking costs and eliminate the need to increase parking fees because it would be easier to pay at one time than to have to continually be coming up with the money. This policy would save the students and the university money because the current parking garage gates would not need to be adjusted or replaced to accept a different amount of money. The money could be used more efficiently because it could be invested or spent immediately, rather than the university collecting smaller amounts of money over the course of the semester.

Persuasive Strong

Reasonable Unconvincing

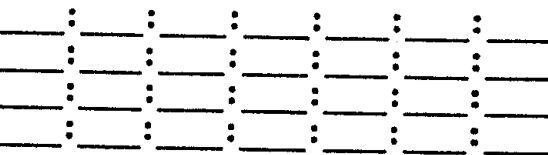
Lacking in Persuasiveness Weak Unreasonable Convincing

Employees and students should not be required to provide their employers and/or schools with the results of an AIDS detection test because it will cause people's insurance rates to go up. The testing would be boring and tedious work. Besides, nobody needs to know what disease someone else has.

Reasonable
Persuasive
Weak $\square$
Unconvincing


Students should not be required to take comprehensive examinations in order to graduate from college because a paper and pencll test cannot accurately measure the performance skills necessary to most careers. It would be impossible to develop a test that would be fair to everyone. Additionally, it would be redundant to test students on subject matter from classes that they have

already passed.

$\begin{array}{r}\text { Persuasive } \\ \text { Strong }\end{array}$ Unconvincing
Reasonable

An additional $\$ 50.00$ should not be added to the registration fees in order to defray parking costs and eliminate the need to raise parking fees because it will upset the students. The school doesn't really need the money. It's a free country and I ought to be able to park where I want to without paying extra for it. Unconvincing Unreasonable Persuasive Weak

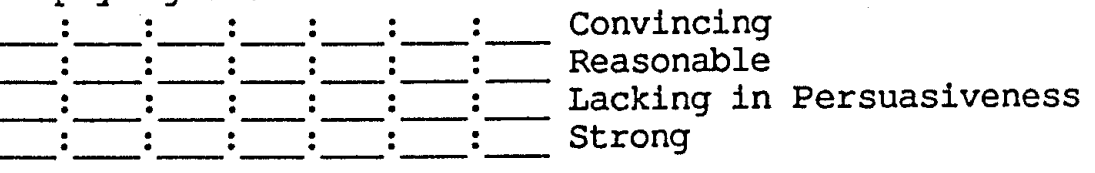


Appendix B

Experiment 1

Stimulus Items 
Over the past year a number of groups have been formed on this campus to discuss a variety of different issues. Below is an excerpt from a typical discussion on a particular issue. In it, an experimenter has interrupted the group in order to poll its members.

The excerpt you will be reading is from a discussion on the issue of requiring comprehensive examinations for graduation from college. This issue is being discussed for possible implementation at San Jose State University in Fall, 1988.

Excerpt From a Group Discussion of Comprehensive Examinations Experimenter: Excuse me, would you please each tell me how you feel about this issue?

Participant 1: Comprehensive examinations should be a requirement for graduation from college because graduates who have taken comprehensive examinations are ranked as more desirable by most employers so this policy would improve job opportunities for gracuates. Comprehensive examinations would give students incentive to study harder and learn more. This policy would also insure that graduates have adequate skill levels.

Participant 2: Students should not be required to take comprehensive examinations in order to graduate from college because it will give them bad memories of school. It would also cause many students to lose large amounts of sleep while studying. College students take enough exams already.

Participant 3: I would have to agree with (Participant 1) that students should be required to take comprehensive examinations in order to graduate from college.

Participant 4: I think students should be required to take comprehensive examinations, also. I agree with (Participant 1), too. 
Over the past year a number of groups have been formed on this campus to discuss a variety of different issues. Below is an excerpt from a typical discussion on a particular issue. In it, an experimenter has interrupted the group in order to poll its members.

The excerpt you will be reading is from a discussion on the issue of requiring comprehensive examinations for graduation from college. This issue is being discussed for possible implementation at San Jose State University in Fall, 1988.

Excerpt From a Group Discussion of Comprehensive Examinations Experimenter: Excuse me, would you please each tell me how you feel about this issue?

Participant 1: Comprehensive examinations should be a requirement for graduation from college because college students have it too easy right now. A comprehensive examination will let the student know if he/she is any good. Also, testing builds character.

Participant 2: Students should not be required to take comprehensive examinations in order to graduate from college because a paper and pencil test cannot accurately measure the performance skills necessary to most careers. It would be impossible to develop a test that would be fair to everyone. Additionally, it would be rechundant to test students on subject matter from classes that they have already passed.

Participant 3: I would have to agree with (Participant 1) that students should be required to take comprehensive examinations in order to graduate from college.

Participant 4: I think students should be required to take comprehensive examinations, also. I agree with (Participant 1), too. 
Over the past year a number of groups have been formed on this campus to discuss a variety of different issues. Below is an excerpt from a typical discussion on a particular issue. In it, an experimenter has interrupted the group in order to poll its members.

The excerpt you will be reading is from a discussion on the issue of requiring comprehensive examinations for graduation from college. This issue is being discussed for possible implementation at San Jose State University in Fall, 1988.

Excerpt From a Group Discussion of Comprehensive Examinations Experimenter: Excuse me, would you please each tell me how you feel about this issue?

Participant 1: Students should not be required to take comprehensive examinations in order to gracuate from college because a paper and pencil test cannot accurately measure the performance skills necessary to most careers. It would be impossible to develop a test that would be fair to everyone. Additionally, it would be redundant to test students on subject matter from classes that they have already passed.

Participant 2: Comprehensive examinations should be a requirement for graduation from college because college students have it too easy right now. A comprehensive examination will let the student know if he/she is any good. Also, testing builds character.

Participant 3: I would have to agree with (Participant 1) that students should not be required to take comprehensive examinations in order to graduate from college.

Participant 4: I think students should not be required to take comprehensive examinations, also. I agree with (Participant 1), too. 
Over the past year a number of groups have been formed on this campus to discuss a variety of different issues. Below is an excerpt from a typical discussion on a particular issue. In it, an experimenter has intermuted the group in order to poll its members.

The excerpt you will be reading is from a discussion on the issue of requiring comprehensive examinations for graduation from college. This issue is being discussed for possible implementation at San Jose State University in Fall, 1988.

Excerpt From a Group Discussion of Comprehensive Examinations Experimenter: Excuse me, would you please each tell me how you feel about this issue?

Participant 1: Students should not be required to take comprehensive examinations in order to gracuate from college because it will give them bad memories of school. It would also cause many students to lose large amounts of sleep while studying. College students take enough exams already.

Participant 2: Cormprehensive examinations should be a requirement for graduation from college because graduates who have taken comprehensive examinations are ranked as more desirable by most employers so this policy would improve job opportunities for graduates. Comprehensive examinations would give students incentive to study harder and learn more. This policy would also insure that graduates have adequate skill levels.

Participant 3: I would have to agree with (Participant 1) that students should not be required to take comprehensive examinations in order to graduate from college.

Participant 4: I think students should not be required to take comprehensive examinations, also. I agree with (Participant 1), too. 
Over the past year a number of groups have been formed on this campus to discuss a variety of different issues. Below is an excerpt from a typical discussion on a particular issue. In it, an experimenter has interrupted the group in order to poll its members.

The excerpt you will be reading is from a discussion on the issue of requiring comprehensive examinations for graduation from college. This issue is being discussed for possible implementation at San Jose State University in Fall, 1988.

Excenpt Erom a Group Discussion of Comprehensive Examinations Experimenter: Excuse me, would you please each tell me how you feel about this issue?

Participant 1: Students should not be required to take comprehensive examinations in order to graduate from college because a paper and pencil test cannot accurately measure the performance skills necessary to most careers. It would be impossible to develop a test that would be fair to everyone. Additionally, it would be redundant to test students on subject matter from classes that they have already passed.

Participant 2: Comprehensive examinations should be a requirement for graduation from college because college students have it too easy right now. A comprehensive examination will let the student know if he/she is any good. Also, testing builds character.

Participant 3: I would have to agree with (Participant 1) that students should not be required to take comprehensive examinations in order to gracuate from college.

Participant 4: I think students should be required to take comprehensive examinations, also. I'm afraid I would have to agree with (Participant 2). 
Over the past year a number of groups have been formed on this campus to discuss a variety of different issues. Below is an excerpt from a typical discussion on a particular issue. In it, an experimenter has interrupted the group in order to poll its members.

The excerpt you will be reading is from a discussion on the issue of requiring comprehensive examinations for graduation from college. This issue is being discussed for possible implementation at San Jose State University in Fall, 1988.

Excerpt From a Group Discussion of Comprehensive Examinations Experimenter: Excuse me, would you please each tell me how you feel about this issue?

Participant 1: Students should not be required to take comprehensive examinations in order to graduate from college because it will give them bad memories of school. It would also cause many students to lose large amounts of sleep while studying. College students take enough exams already.

Participant 2: Comprehensive examinations should be requirement for graduation from college because graduates who have taken comprehensive examinations are ranked as more desirable by most employers so this policy would improve job opportunities for graduates. Comprehensive examinations would give students incentive to study harder and learn more. This policy would also insure that graduates have adequate skill levels.

Participant 3: I would have to agree with (Participant 1) that students should not be required to take comprehensive examinations in order to graduate from college.

Participant 4: I think students should be required to take comprehensive examinations, also. I'm afraid I would have to agree with (Participant 2). 
Over the past year a number of groups have been formed on this campus to discuss a variety of different issues. Below is an excerpt from a typical discussion on a particular issue. In it, an experimenter has interrupted the group in order to poll its members.

The excerpt you will be reading is from a discussion on the issue of requiring comprehensive examinations for graduation from college. This issue is being discussed for possible implementation in the State of Georgia in Fall, 1991.

Excerpt From a Group Discussion of Comprehensive Examinations Experimenter: Excuse me, would you please each tell me how you feel about this issue?

Participant 1: Comprehensive examinations should be a requirement for graduation from college because graduates who have taken comprehensive examinations are ranked as more desirable by most employers so this policy would improve job opportunities for graduates. Comprehensive examinations would give students incentive to study harder and learn more. This policy would also insure that graduates have adequate skill levels.

Participant 2: Students should not be required to take comprehensive examinations in order to graduate from college because it will give them bad memories of school. It would also cause many students to lose large amounts of sleep while studying. College students take enough exams already.

Participant 3: I would have to agree with (Participant 1) that students should be required to take comprehensive examinations in order to gracuate from college.

Participant 4: I think students should be required to take comprehensive examinations, also. I agree with (Participant 1), too. 
Over the past year a number of groups have been formed on this campus to discuss a variety of different issues. Below is an excerpt from a typical discussion on a particular issue. In it, an experimenter has interrupted the group in order to poll its members.

The excerpt you will be reading is from a discussion on the issue of requiring comprehensive examinations for graduation from college. This issue is being discussed for possible implementation in the State of Georgia in Fall, 1991.

Excerpt From a Group Discussion of Comprehensive Examinations Experimenter: Excuse me, would you please each tell me how you feel about this issue?

Participant 1: Comprehensive examinations should be a requirement for graduation from college because college students have it too easy right now. A comorehensive examination will let the student know if he/she is any good. Also, testing builds character.

Participant 2: Students should not be required to take comprehensive examinations in order to graduate from college because a paper and pencil test cannot accurately measure the performance skills necessary to most careers. It would be impossible to develop a test that would be fair to everyone. Additionally, it would be redundant to test students on subject matter from classes that they have already passed.

Participant 3: I would have to agree with (Participant 1) that students should be required to take comprehensive examinations in order to graduate from college.

Participant 4: I think students should be required to take comprehensive examinations, also. I agree with (Participant 1), too. 
Over the past year a number of groups have been formed on this campus to discuss a variety of different issues. Below is an excerpt from a typical discussion on a particular issue. In it, an experimenter has internupted the group in order to poll its members.

The excerpt you will be reading is from a discussion on the issue of requiring comprehensive examinations for graduation from college. This issue is being discussed for possible implementation in the State of Georgia in Fall, 1991.

Excerpt From a Group Discussion of Comprehensive Examinations Experimenter: Excuse me, would you please each tell me how you feel about this issue?

Participant 1: Students should not be required to take comprehensive examinations in order to graduate from college because a paper and pencil test cannot accurately measure the performance skills necessary to most careers. It would be impossible to develop a test that would be fair to everyone. Additionally, it would be redundant to test students on subject matter from classes that they have already passed.

Participant 2: Comprehensive examinations should be a requirement for graduation from college because college students have it too easy right now. A comprehensive examination will let the student know if he/she is any good. Also, testing builds character.

Participant 3: I would have to agree with (Participant 1) that students should not be required to take comprehensive examinations in order to graduate from college.

Participant 4: I think students should not be required to take comprehensive examinations, also. I agree with (Participant 1), too. 
Over the past year a number of groups have been formed on this campus to discuss a variety of different issues. Below is an excerpt from a typical discussion on a particular issue. In it, an experimenter has interrupted the group in order to poll its members.

The excerpt you will be reading is from a discussion on the issue of requiring comprehensive examinations for graduation from college. This issue is being discussed for possible implementation in the State of Georgia in Fall, 1991.

Excenpt From a Group Discussion of Comprehensive Examinations Experimenter: Excuse me, would you please each tell me how you feel about this issue?

Participant 1: Students should not be required to take comprehensive examinations in order to graduate from college because it will give them bad memories of school. It would also cause many students to lose large amounts of sleep while studying. College students take enough exams already.

Participant 2: Comprehensive examinations should be a requirement for graduation from college because gracuates who have taken comprehensive examinations are ranked as more desirable by most employers so this policy would improve job opportunities for graduates. Comprehensive examinations would give students incentive to study harder and learn more. This policy would also insure that graduates have adequate skill levels.

Participant 3: I would have to agree with (Participant 1) that students should not be required to take comprehensive examinations in order to graduate from college.

Participant 4: I think students should not be required to take comprehensive examinations, also. I agree with (Participant 1), too. 
Over the past year a number of groups have been formed on this campus to discuss a variety of different issues. Below is an excerpt from a typical discussion on a particular issue. In it, an experimenter has interrupted the group in order to poll its members.

The excerpt you will be reading is from a discussion on the issue of requiring comprehensive examinations for graduation from college. This issue is being discussed for possible implementation in the State of Georgia in Fall, 1991.

Excerpt From a Group Discussion of Comprehensive Examinations Experimenter: Excuse me, would you please each tell me how you feel about this issue?

Participant 1: Students should not be required to take comprehensive examinations in order to gracuate from college because a paper and pencil test cannot accurately measure the performance skills necessary to most careers. It would be impossible to develop a test that would be fair to everyone. Additionally, it would be redundant to test students on subject matter from classes that they have already passed.

Participant 2: Comprehensive examinations should be a requirement for graduation from college because college students have it too easy right now. A comprehensive examination will let the student know if he/she is any good. Also, testing builds character.

Participant 3: I would have to agree with (Participant 1) that students should not be required to take comprehensive examinations in order to graduate from college.

Participant 4: I think students should be required to take comprehensive examinations, also. I'm afraid I would have to agree with (Participant 2). 
Over the past year a number of groups have been formed on this campus to discuss a variety of different issues. Below is an excerpt from a typical discussion on a particular issue. In it, an experimenter has interrupted the group in order to poll its members.

The excerpt you will be reading is from a discussion on the issue of requiring comprehensive examinations for graduation from college. This issue is being discussed for possible implementation in the State of Georgia in Fall, 1991.

Excerpt From a Group Discussion of Comprehensive Examinations Experimenter: Excuse me, would you please each tell me how you feel about this issue?

Participant 1: Students should not be required to take comprehensive examinations in order to graduate from college because it will give them bad memories of school. It would also cause many students to lose large amounts of sleep while studying. College students take enough exams already.

Participant 2: Comprehensive examinations should be a requirement for graduation from college because graduates who have taken comprehensive examinations are ranked as more desirable by most employers so this policy would improve job opportunities for graduates. Comprehensive examinations would give students incentive to study harder and learn more. This policy would also insure that graduates have adequate skill levels.

Participant 3: I would have to agree with (Participant 1) that students should not be required to take comprehensive examinations in order to graduate from college.

Participant 4: I think students should be required to take comprehensive examinations, also. I'm afraid I would have to agree with (Participant 2). 


\section{Appendix C}

Posttest Instruments for

Experiment 1 and Experiment 2 
I think that the policy of requiring students to take a comprehensive examination in order to graduate from college is:

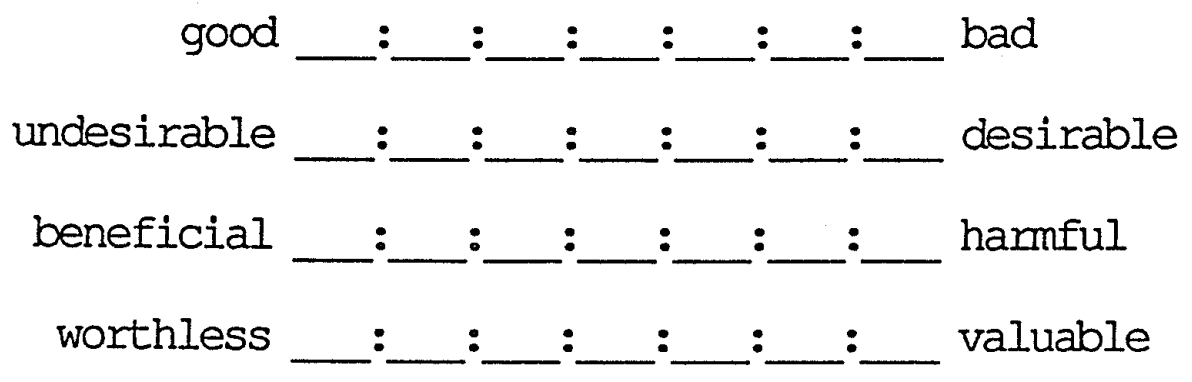

In the preceeding discussion the majority was:

In favor of comprehensive examinations

Opposed to comprehensive examinations

There was no majority 
The arguments supporting the comprehensive examination requirement were:

$\begin{aligned} & \text { Reasonable } \\ & \text { Persuasive } \\ & \text { Weak }\end{aligned}$ Unconvincing $\square$

The arguments opposing the comprehensive examination requirement were:

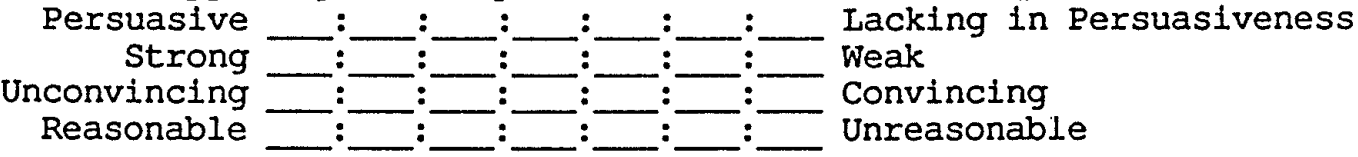

While reading the message were you:
A. Attempting to analyze the issues in the message.
B. Not very attentive to the ideas. :______ Disagree
C. Deep in thought about the message.
D. Unconcerned with the ideas

:___________ Disagree Agree : : : : : : : : : : : D Disagree
E. Extending a good deal of cognitive effort. Agree : : : : : : : : : : Disagree
F. Distracted by other thoughts not related to the message.
G. Not really exerting $: \frac{\text { Agree }}{\text { your mind. }}$ Agree : : : : : : : : Disagree
H. Doing your best to think about what was written.
I. Reflecting on the implications of the arguments.
J. Resting your mind. Agree ___________________ Disagree
K. Searching your mind in response $\overline{\text { to the }}$ ideas.

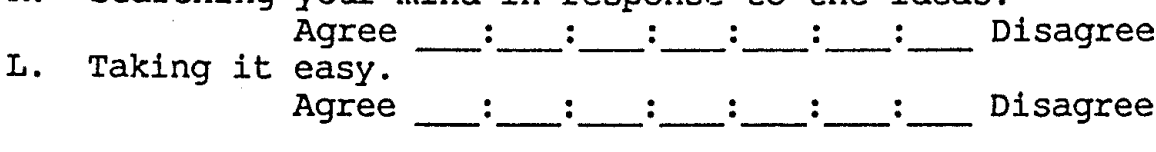 Disagree

How important is the issue in this discussion to you? Important Very Important Not at all

To what extent do you expect this issue to have significant consequences for your life? Very Significant _ ____________ Not at all Significant

What level of personal meaning does this issue have for you? Not at all Meaningful : : : : : Very Meaningful 
Appendix D Experiment 2

Stimulus Items 
You should not feel that you need to think a lot or put much effort into this task just because it is research. We would like you to respond as if you were in on the group discussion. Consider this a chance to sit back and relax.

Imagine that, recently a coalition of small, private, liberal arts colleges, such as the University of the Pacific in the Stockton area and Simpson College in San Francisco, has become concerned by accusations of low academic standards. Since such a reputation affects both a university's revenue and the employment opportunities available to graduates of the university, a comittee has been formed to explore possible solutions to this problem. One proposed option is to require seniors to pass a comprehensive examination in their declared major prior to graduation.

If this proposal for passing a comprehensive examination prior to graduation is accepted, it would be developed and refined over the next decade and the tests would be implemented in the year 2000.

A number of student focus groups have been formed to discuss the positive and negative aspects of comprehensive examinations. In an effort to gather the opinions of students who will not be affected in any way if those schools require passing a comprehensive examination for graduation, you are being asked to read a short transcript from one of these group discussions and answer some questions about it. While reading the script, try to imagine yourself as a group member in on the discussion. After reading the transcript, please respond to the questions by indicating your opinions about the topics and issues raised in the group discussion. For each question, please respond to every scale.

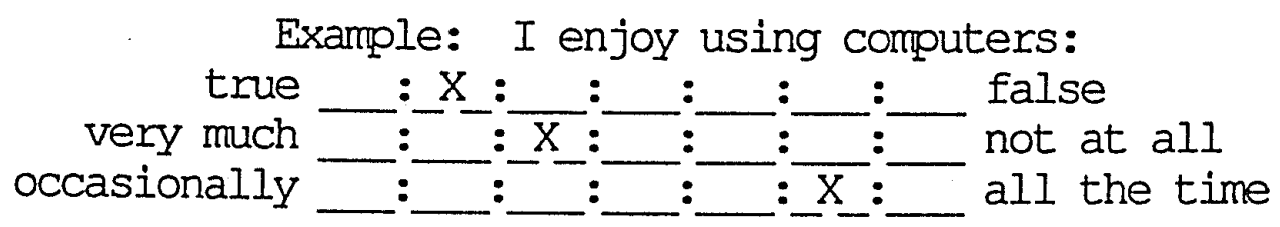


You should not feel that you need to think a lot or put much effort into this task just because it is research. We would like you to respond as if you were in on the group discussion. Consider this a chance to sit back and relax.

Imagine that, recently the board of regents of the California State University system, which includes San Jose State University, California State University at Hayward, and seventeen other universities, has become concerned by accusations of low academic standards. Since such a reputation affects both a university's revenue and the employment opportunities available to graduates of the university, a committee has been formed to explore possible solutions to this problem. One proposed option is to require seniors to pass a comprehensive examination in their declared major prior to graduation.

If this proposal for passing a comprehensive examination prior to graduation is accepted, it would be developed and refined over the summer and put into effect in the Fall semester of 1988.

A number of student focus groups have been formed to discuss the positive and negative aspects of comprehensive examinations. In an effort to gather the opinions of students who could be affected in many ways if the proposal to require passing a comprehensive examination prior to graduation is accepted, you are being asked to read a short transcript from one of these group discussions and answer some questions about it. While reading the script, try to imagine yourself as a group member in on the discussion. After reading the transcript, please respond to the questions by indicating your opinions about the topics and issues raised in the group discussion. For each question, please respond to every scale.

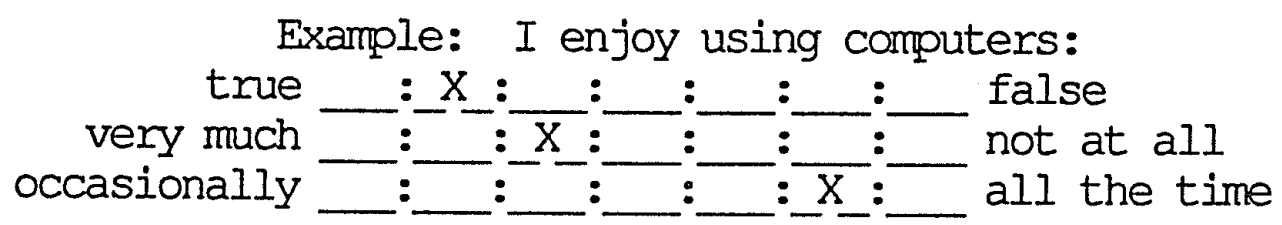




\section{Excerpt From A Group Discussion of Comprehensive Examinations}

In the excerpt that you will be reading, an instructor has interrupted the group discussion to survey the attitudes of the group members.

Instructor: Excuse me, would you each please tell me how you feel about this issue. If there is some disagreement, perhaps two people could summarize the reasons for their positions and others could indicate who they agree with.

Participant 1: I think that passing a comprehensive examination should be required for graduation because universities with the exams attract larger and better known corporations to recruit students for jobs. Average starting salaries are higher for graduates of schools with the exams. In addition, a tuition increase would be avoided because the state legislature would increase financial support if the exams are instituted.

Participant 2: I think that seniors should not be required to pass a comprehensive examination in order to graduate from college because if this is their final undergracuate experience it will give them bad memories of college. It would also cause many students to lose large amounts of sleep while staying up late to study. Besides, college students take enough exams already.

Participant 3: I agree with (Participant 1). I think students should be required to pass a comprehensive examination in order to graduate.

Participant 4: I also think students should be required to pass a comprehensive examination in order to graduate.

Participant 5: I feel the same way. I think students should be required to pass a comprehensive examination to graduate.

Participant 6: I agree with the majority. I think passing a comprehensive examination should be a requirement for graduation.

Instructor: Alright, I see that after discussing the issue, the majority of the group is in favor of requiring students to pass a comprehensive examination to graduate. Thank you very much for your participation. 


\section{Excerpt From A Group Discussion of Comprehensive Examinations}

In the excerpt that you will be reading, an instructor has interrupted the group discussion to survey the attitudes of the group members.

Instructor: Excuse me, would you each please tell me how you feel about this issue. If there is some disagreement, perhaps two people could summarize the reasons for their positions and others could indicate who they agree with.

Participant 1: I think that seniors should be required to pass a comprehensive examination in order to graduate from college because graduate students are complaining that since they have to take comprehensives, undergraduates should have to take them also. Comprehensive exams area tradition dating back to the ancient Greeks. Besides, testing is good for building a person's character.

Participant 2: I think that seniors should not be required to pass a comprehensive examination because a paper and pencil test cannot accurately measure the performance skills necessary to most careers. It would be impossible to develop tests that were fair to everyone. It would also be redundant to test students on material from classes that they have already passed.

Participant 3: I agree with (Participant 1). I think students should be required to pass a comprehensive examination in order to graduate.

Participant 4: I also think students should be required to pass a comprehensive examination in order to graduate.

Participant 5: I feel the same way. I think students should be required to pass a comprehensive examination to graduate.

Participant 6: I agree with the majority. I think passing a comprehensive examination should be a requirement for graduation.

Instructor: Alright, I see that after discussing the issue, the majority of the group is in favor of requiring students to pass a comprehensive examination to graduate. Thank you very much for your participation. 
Excerpt From A Group Discussion of Comprehensive Examinations

In the excerpt that you will be reading, an instructor has interrupted the group discussion to survey the attitudes of the group members.

Instructor: Excuse me, would you each please tell me how you feel about this issue. If there is some disagreement, perhaps two people could summarize the reasons for their positions and others could indicate who they agree with.

Participant 1: I think that seniors should not be required to pass a comprehensive examination in order to graduate from college because if this is their final undergraduate experience it will give them bad memories of college. It would also cause many students to lose large amounts of sleep while staying up late to study. Besides, college students take enough exams already.

Participant 2: I think that passing a comprehensive examination should be required for graduation because universities with the exams attract larger and better known corporations to recruit students for jobs. Average starting salaries are higher for graduates of schools with the exams. In addition, a tuition increase would be avoided because the state legislature would increase financial support if the exams are instituted.

Participant 3: I agree with (Participant 1). I think students should not be required to pass a comprehensive examination in order to graduate.

Participant 4: I also think students should not be required to pass a comprehensive examination in order to graduate.

Participant 5: I feel the same way. I think students should not be required to pass a comprehensive examination to graduate.

Participant 6: I agree with the majority. I think passing a comprehensive examination should not be a requirement for graduation.

Instructor: Alright, I see that after discussing the issue, the majority of the group is opposed to requiring students to pass a comprehensive examination to graduate. Thank you very much for your participation. 
Excerpt From A Group Discussion of Comprehensive Examinations

In the excerpt that you will be reading, an instructor has interrupted the group discussion to survey the attitudes of the group members.

Instructor: Excuse me, would you each please tell me how you feel about this issue. If there is some disagreement, perhaps two people could summarize the reasons for their positions and others could indicate who they agree with.

Participant 1: I think that seniors should not be required to pass a comprehensive examination because a paper and pencil test cannot accurately measure the performance skills necessary to most careers. It would be impossible to develop tests that were fair to everyone. It would also be redundant to test students on material from classes that they have already passed.

Participant 2: I think that seniors should be required to pass a comprehensive examination in order to graduate from college because graduate students are complaining that since they have to take comprehersives, undergraduates should have to take them also. Comprehensive exams area tradition dating back to the ancient Greeks. Besides, testing is good for building a person's character.

Participant 3: I agree with (Participant 1). I think students should not be required to pass a comprehensive examination in order to graduate.

Participant 4: I also think students should not be required to pass a comprehensive examination in order to graduate.

Participant 5: I feel the same way. I think students should not be required to pass a comprehensive examination to graduate.

Participant 6: I agree with the majority. I think passing a comprehensive examination should not be a requirement for graduation.

Instructor: Alright, I see that after discussing the issue, the majority of the group is opposed to requiring students to pass a comprehensive examination to graduate. Thank you very much for your participation. 
Excerpt From A Group Discussion of Comprehensive Examinations

In the excerpt that you will be reading, an instructor has interrupted the group discussion to survey the attitudes of the group members.

Instructor: Excuse me, would you each please tell me how you feel about this issue. If there is some disagreement, perhaps two people could summarize the reasons for their positions and others could indicate who they agree with.

Participant 1: I think that seniors should not be required to pass a comprehensive examination in order to graduate from college because if this is their final undergraduate experience it will give them bad memories of college. It would also cause many students to lose large amounts of sleep while staying up late to study. Besides, college students take enough exams already.

Participant 2: I think that passing a comprehensive examination should be required for graduation because universities with the exams attract larger and better known corporations to recruit students for jobs. Average starting salaries are higher for graduates of schools with the exams. In addition, a tuition increase would be avoided because the state legislature would increase financial support if the exams are instituted.

Participant 3: I agree with (Participant 2). I think students should be required to pass a comprehensive examination in order to graduate.

Participant 4: I agree with (Participant 1). I think that students should not be required to pass a comprehensive examination to graduate.

Participant 5: I think students should be required to pass a comprehensive examination in order to graduate.

Participant 6: It looks like we're even. I think passing a comprehensive examination should not be a requirement for graduation.

Instructor: Alright, I see that after discussing the issue, there is no majority in favor of or opposed to requiring students to pass a comprehensive examination to graduate. Thank you very much for your participation. 


\section{Excerpt From A Group Discussion of Comprehensive Examinations}

In the excerpt that you will be reading, an instructor has interrupted the group discussion to survey the attitudes of the group members.

Instructor: Excuse me, would you each please tell me how you feel about this issue. If there is some disagreement, perhaps two people could summarize the reasons for their positions and others could indicate who they agree with.

Participant 1: I think that senfors should not be required to pass a comprehensive examination because a paper and pencil test cannot accurately measure the performance skills necessary to most careers. It would be impossible to develop tests that were fair to everyone. It would also be redundant to test students on material from classes that they have already passed.

Participant 2: I think that seniors should be required to pass a comprehensive examination in order to graduate from college because graduate students are complaining that since they have to take comprehensives, undergraduates should have to take them also. Comprehensive exams area tradition dating back to the ancient Greeks. Besides, testing is good for building a person's character.

Participant 3: I agree with (Participant 2). I think students should be required to pass a comprehensive examination in order to graduate.

Participant 4: I agree with (Participant 1). I think that students should not be required to pass a comprehensive examination to graduate.

Participant 5: I think students should be required to pass a comprehensive examination in order to graduate.

Participant 6: It looks like we're even. I think passing a comprehensive examination should not be a requirement for graduation.

Instructor: Alright, I see that after discussing the issue, there is no majority in favor of or opposed to requiring students to pass a comprehensive examination to graduate. Thank you very much for your participation. 
Appendix E

Human Subjects

Approval Form 
Human Subjects Institutional Review Board Project Proposal Review

I, the undersigned member of the San Jose State University Human Subjects

Institutional Review Board, have reviewed the following proposal submitted to the Committee on March 22, 1988 by:

Principal Investigator Stephen A. March

Protócol \# 7283

Project Titie "THE EFFECTS OF ISSUE-INVOLVEIIENT, MAJORITY POSITION AND ARGUMENT QUALITY ON CHOICE SIFT.

I recommend the following action (indicate one):

1. Approved for clearance as involving minimal risk to Human Subjects

2. Approved for clearance with risk to Human Subjects

3. Approved for clearance when the following conditions are met:

4. Return to principal investigator for following reasons:

5. Expedited review (specify conditions(s) that merit expedited review):

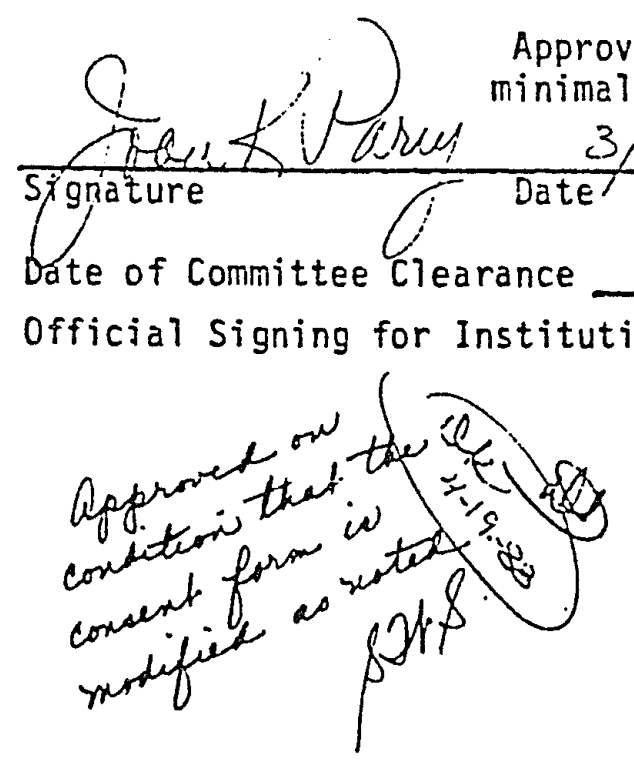

San Jose State University Foundation

One Washington Square

San Jose, CA 95192-0139

(408) 924-1400

* Return to SJSUF for full HSIRB review: 